\title{
Host-Directed Drug Therapies for Neglected Tropical Diseases Caused by Protozoan Parasites
}

\author{
Sanjay Varikuti't, Bijay Kumar Jha ${ }^{2 t}$, Greta Volpedo ${ }^{1,3+}$, Nathan M. Ryan', \\ Gregory Halsey ${ }^{1}$, Omar M. Hamza ${ }^{1}$, Bradford S. McGwire ${ }^{2}$ and Abhay R. Satoskar ${ }^{1,3 *}$ \\ 'Department of Pathology, Wexner Medical Center, The Ohio State University, Columbus, OH, United States, ${ }^{2}$ Division \\ of Infectious Diseases, Department of Internal Medicine, The Ohio State University, Columbus, $\mathrm{OH}$, United States, \\ ${ }^{3}$ Department of Microbiology, The Ohio State University, Columbus, $\mathrm{OH}$, United States
}

OPEN ACCESS

Edited by:

Wanderley De Souza,

Universidade Federal

do Rio de Janeiro, Brazil

Reviewed by:

Julio A. Urbina,

Instituto Venezolano

de Investigaciones Científicas (IVIC),

Venezuela

Hemanta K. Majumder Indian Institute of Chemical Biology (CSIR), India

Maria De Nazaré Correia Soeiro, Fundação Oswaldo Cruz (Fiocruz),

Brazil

*Correspondence:

Abhay R. Satoskar

abhay.satoskar@osumc.edu

${ }^{\dagger}$ Co-first authors

Specialty section:

This article was submitted to

Microbial Immunology,

a section of the journal

Frontiers in Microbiology

Received: 21 May 2018 Accepted: 17 October 2018 Published: 30 November 2018

Citation:

Varikuti S, Jha BK, Volpedo $G$, Ryan NM, Halsey G, Hamza OM, McGwire BS and Satoskar AR (2018)

Host-Directed Drug Therapies for Neglected Tropical Diseases

Caused by Protozoan Parasites.

Front. Microbiol. 9:2655.

doi: 10.3389/fmicb.2018.02655
The neglected tropical diseases (NTDs) caused by protozoan parasites are responsible for significant morbidity and mortality worldwide. Current treatments using anti-parasitic drugs are toxic and prolonged with poor patient compliance. In addition, emergence of drug-resistant parasites is increasing worldwide. Hence, there is a need for safer and better therapeutics for these infections. Host-directed therapy using drugs that target host pathways required for pathogen survival or its clearance is a promising approach for treating infections. This review will give a summary of the current status and advances of host-targeted therapies for treating NTDs caused by protozoa.

Keywords: leishmaniasis, Chagas disease, Human African Trypanosomiasis, host-directed therapy, treatment

\section{INTRODUCTION TO NEGLECTED TROPICAL DISEASES}

The neglected tropical diseases (NTDs) comprise a group including 20 different illnesses which currently affect over a billion individuals and amount to approximately $12 \%$ of the total global health burden across 149 tropical and subtropical countries (Chappuis et al., 2007; Ready, 2014; Mello et al., 2017). In humans, NTDs impair cognitive and physical development, cause development of chronic physical or emotional conditions, and could result in an increased mortality and morbidity having a significant economic impact on the economy in developing countries (Centers for Disease Control and Prevention, 2017; World Health Organization, 2018).

In this review we focus on three NTDs caused by different but related to protozoa which account for the highest death toll amongst all NTDs (Hotez et al., 2007): Leishmaniasis, caused by multiple species of the Leishmania; Chagas disease, caused by Trypanosoma cruzi; and Human African trypanosomiasis (HAT), caused by either Trypanosoma brucei gambiense or Trypanosoma brucei rhodesiense. According to the World Health Organization (WHO), these three NTDs require "Innovative and Intensified Disease Management (IDM)" approaches due to lacking research and development investments as well as a deficiency of effective control tools in endemic areas (Hotez et al., 2007).

Many NTDs are not a major concern in the most developed countries, but they continue to persist in areas where people live with poor sanitation and hygiene and remain in close contact with insect vectors and infected reservoir hosts. Tourists and military personnel traveling to endemic areas are also exposed to these infections and pose a risk of contracting them. Reports show that hundreds of US troops deployed in endemic areas such as Iraq have contracted cutaneous or visceral leishmaniasis (Weina et al., 2004). Additionally, immigration and increased exchanges of economic 
and social nature between different countries have contributed to the globalization of some NTDs such as Chagas disease (KalilFilho, 2015).

Leishmania and Trypanosoma not only infect humans but they also infect wild and domesticated animals, which serve as reservoirs for these diseases. Carnivores, rodents and lagomorphs have been identified as reservoirs for leishmaniasis in Europe, but the dog remains the main domestic reservoir, especially for L. infantum (Millan et al., 2014). Relocated or traveling dogs have been shown to bring $L$. infantum to non-endemic areas, spreading the disease throughout Europe (Maia and Cardoso, 2015). Along with the Mediterranean area, zoonotic leishmaniasis can be found in the Middle East, West Africa, Central Asia and the Americas. Here again wild animals and dogs are mainly responsible for L. infantum transmission (Harhay et al., 2011). Similarly, Trypanosoma can also infect a wide variety of domesticated and wild animals. For example, the presence of a widespread T. cruzi infection has been reported along the Texas-Mexico border in government working dogs (Meyers et al., 2017). In Uganda, the spread of sleeping sickness caused by T. brucei rhodesiense has been traced to infected cattle movement (Selby et al., 2013). Additionally, cases of horses infected with T. evansi, causative agent of the chronic wasting disease surra, have been reported in Brazil and other areas (Elshafie et al., 2013; Parreira et al., 2016). The widespread infection of livestock and other animals increases the risk of transmission to humans, severely impacting whole regions with the potential for global effect. Furthermore, animal infection can lead to infertility and loss of livestock resulting significant economic losses in many African, Asian and American countries (Giordani et al., 2016).

Despite the high prevalence of these three diseases, currently only a handful of treatments available against these parasites and many of those exhibit high toxicity due to the biomolecular similarities between eukaryotic parasites and mammalian cells, as well as to the accumulation of toxic derivative products of the therapeutic compounds. For instance, it is known that the toxicity of benznidazole and nifurtimox, established drugs for Chagas disease, is due to the metabolic conversion occurring after enzymatic reduction of nitro-groups (Bermudez et al., 2016). Another problem associated with some of these drugs is the increasing parasitic resistance as a result of adaptation. Resistance can arise due to different mechanisms such as target modifications, decreased drug uptake or increased efflux and augmented drug metabolism (Yasinzai et al., 2013). Several of these mechanisms, and a combination of them, have been documented in Leishmania parasites resistant to antimonials ( $\mathrm{Sb}^{\mathrm{III}}$, trivalent form reduced from the pentavalent form), miltefosine and amphotericin B (Ponte-Sucre et al., 2017). For example, reduced expression of the $\mathrm{Sb}^{\mathrm{III}}$ transporter AQP1 leads to increased resistance to antimonials. Additionally, the uptaken $\mathrm{Sb}^{\mathrm{III}}$ can be bound by the thiol compound trypanothione, present in Leishmania, and either sequestered or expelled from the cell via specific efflux pumps (Ponte-Sucre et al., 2017). Furthermore, increased expression of ABCG-like transporter TcABCG1 in T. cruzi confers resistance to benznidazole (Zingales et al., 2015).
Because of these concerns, it is imperative to find new therapeutics with low toxicity for the human host while maintaining high anti-parasitic efficacy. This review focuses on host-targeted approaches to treat NTDs caused by these three protozoan parasites.

\section{HOST-TARGETED THERAPEUTICS}

Host-targeted drugs bypass many of the problems encountered by treatments that specifically target parasites, by acting directly on host molecules or pathways that are redundant for the host but critical for pathogen invasion, survival and replication. Such approaches are likely to have a less chance of developing resistance as the host molecules and processes mutate at lower rates than most pathogens. Additionally, because these drugs act on the host, and not on specific pathogens, these treatments may be broad-spectrum and effective against several pathogens.

Different strategies have been employed to identify new host targets. The broader and more general approaches are transcriptomic and proteomic analysis as well as the assessment of microRNA, small interfering RNA (siRNA) and short hairpin RNA expression profiles (Prudencio and Mota, 2013; Krishnan and Garcia-Blanco, 2014). RNA interference in Drosophila has been previously used to identify several host factors manipulated by pathogens to their own advantage. This method was adopted to identify the host factors important for resistance to Listeria monocytogenes and Chlamydia caviae (Prudencio and Mota, 2013). Functional genomics have also been used to study gain or loss of function by over-expressing cDNA or iRNA respectively in mammalian cells to investigate the effects of different phenotypes on pathogenesis of intracellular pathogens. Additionally, hybrid interaction screens can be used to study protein-protein interaction between the host and the pathogen and can help identify potential host targets for drug therapy. Another method used to identify protein-protein as well as protein-RNA interactions is affinity chromatography (Krishnan and Garcia-Blanco, 2014).

Recent studies have identified several host-targeted therapeutics which show promise as novel drugs for treating neglected tropical parasitic infections. These approaches include the use of immuno-modulators, kinase inhibitors, and also natural compounds, which activate pro-inflammatory transcription factors like NF-Kb. Of these treatments, immunomodulators are promising therapeutics not only used by themselves but also in combination with other drugs (Tiuman et al., 2011). In this review we focus on the host-targeted therapy and possible approaches to treat Leishmania, T. brucei, and T. cruzi infections.

\section{LEISHMANIASIS}

Leishmaniasis is a group of tropical diseases caused by protozoan parasites of the genus Leishmania and transmitted via the bite of female Phlebotomine sandflies. This disease affects approximately 12 million people in more than 80 tropical and 
subtropical countries with incidence of reported cases rising rapidly at 2 million cases annually (McGwire and Satoskar, 2014). There are more than 20 different species of Leishmania distributed in both the Old and New World (Centers for Disease Control and Prevention, 2013; World Health Organization, 2018). The clinical manifestations of leishmaniasis depend on many factors including, interactions between the infecting Leishmania species and the immune response of the host, localized or disseminated parasite infection, genetic profile of the parasite and mammalian host, stress and also nutritional status of the host (Locksley et al., 1999; McCall et al., 2013). Cutaneous leishmaniasis (CL) is the most common form of leishmaniasis, which manifests as localized skin lesions that can become chronic, leading to significant tissue destruction and disfigurement. Other forms of infections are mucosal leishmaniasis (ML), or life-threatening visceral leishmaniasis (VL), which is the second most fatal parasitic infection after malaria and is characterized by dissemination of the parasites to liver, spleen and bone marrow (The Center for Food Security and Public Health, 2017).

Although macrophages serve as the preferred host cell for Leishmania, this parasite can also infect other cells like dendritic cells (Woelbing et al., 2006; Contreras et al., 2014), mast cells (Bidri et al., 1997; Lu and Huang, 2017), fibroblasts (Hespanhol et al., 2005) and neutrophils (Mougneau et al., 2011). In particular, neutrophils are recruited within hours of the infection and delay the recruitment of dendritic cells, important for antigen presentation (Hurrell et al., 2015). Neutrophils seem to play an ambivalent role in leishmaniasis; on one hand they serve as host cells, propagating the infection and indirectly hindering antigen presentation (Peters et al., 2008; Hurrell et al., 2015), on the other hand they have been shown to contribute to parasite killing by releasing neutrophil extracellular traps (Mougneau et al., 2011).

\section{HOST IMMUNOLOGY}

A protective immune response against leishmaniasis is characterized by a CD4+ Th1-polarized immune response (Centers for Disease Control and Prevention, 2013). Upon interaction with parasites, antigen presenting cells (APCs) activate T-cells by direct contact as well as by the release of disease-protective cytokines such as interleukin-12 (IL-12). These cytokines prime naïve T-helper cells to differentiate into Th1 cells, the main producers of interferon- $\gamma$ (IFN- $\gamma$ ) (Naman et al., 2018). Natural killer (NK) cells is an another important source of IFN-y that contributes to Th1 cell differentiation and ultimately to disease resolution (Mougneau et al., 2011). IFN- $\gamma$ stimulates phagocytes to produce reactive oxygenand nitrogen-species resulting in parasite killing (Pace, 2014). IFN- $\gamma$, IL-12 and TNF- $\alpha$ are crucial mediators of protection against various forms of Leishmania infection (Naman et al., 2018; World Health Organization, 2018). While a polarized Th1 response is associated with resolution of CL, susceptibility to $\mathrm{CL}$ is associated with an induction of a Th2 immune response. A Th2-polarized immune response is characterized by the production of interleukin-4 (IL-4), IL-13 and interleukin-10
(IL-10). These cytokines, along with TGF- $\beta$ suppress protective immune response and promote parasite and exacerbation of disease (Odiit et al., 1997). In contrast to CL, the resolution of VL requires the production of interleukin-4 (IL-4) and interleukin13 (IL-13) as well as IL-4 $\alpha$ signaling pathway, which induces mature granuloma formation and promotes parasite clearance (Satoskar et al., 1995; Alexander et al., 2000; Stager et al., 2003; McFarlane et al., 2011).

Several drugs are currently used to treat leishmaniasis; but there is no vaccine available for disease prevention. The standard in treatment of leishmaniasis in most endemic countries involves use of pentavalent antimonials such as sodium stibogluconate (SSG). Other drugs, including liposomal amphotericin B, azoles, imiquimod, miltefosine, paromomycin and pentamidine, have also been used with variable success. Unfortunately, the current treatments have several drawbacks, including poor patient compliance due to prolonged treatment duration, high toxicity and emergence of drug resistant parasites (Eugene, 1987; Bray et al., 2003; Torrado et al., 2008; Jhingran et al., 2009; Olliaro and Sundar, 2009; Tiuman et al., 2011; McGwire and Satoskar, 2014; Lamotte et al., 2017; Ponte-Sucre et al., 2017). In this section, we will discuss novel host-targeted drugs to treat leishmaniasis.

\section{HOST-TARGETED THERAPEUTICS AND APPROACHES FOR TREATMENT OF LEISHMANIASIS}

Imatinib is an inhibitor of $\mathrm{Abl} / \mathrm{Arg}$ kinase family of tyrosine kinases, which can directly remodel the actin-based cytoskeleton to mediate phagocytosis (Greuber and Pendergast, 2012; Zhang and Kima, 2016). The Abl/Arg kinases have been previously shown to play a role in phagocytosis of Leishmania amazonensis promastigotes by macrophages (Wetzel et al., 2012). Although treatment with imatinib did not significantly alter cytokine production, reduced the uptake of both opsonized and nonopsonized parasites and led to reduced lesion severity in mice (Wetzel et al., 2012).

Phosphoinositide 3-kinase $\gamma(\mathrm{PI} 3 \mathrm{~K} \gamma$ ) is part of a family of enzymes with the function of phosphorylating lipids containing phosphotidylinositol. PI3K $\gamma$ is expressed in leukocytes and mediates cell migration by initiating actin cytoskeletal reorganization. Because cytoskeletal rearrangement is also critical to phagocytosis, blocking or deleting $\mathrm{PI} 3 \mathrm{~K} \gamma$ results in a significant impairment of parasite entry into phagocytic host cells in vitro and vivo. This decreased phagocytosis, along with an impaired recruitment of cells at the infection site, conferred increased resistance against L. mexicana in C57BL/6 mice. Furthermore, AS-605240, an isoform-selective PI3k $\gamma$ inhibitor, was therapeutically as effective as aforementioned standard anti-leishmanial drug SSG in treating L. mexicana infection (Cummings et al., 2012). A recent study used AS101 (ammonium trichloro [1,2-ethanediolato-O,O']-tellurate), a telluriumbased immunomodulator for the treatment of $L$. donovani infection. Along with a direct effect on promastigotes, AS101 was also shown to reverse T-cell anergy, promote NO and antibody production, and more importantly inhibit the 
STAT3/IL-10 pathway by blocking the PI3k/Atk signaling in infected macrophages. This could further promote MAPK and NF-кB activity (Vishwakarma et al., 2018). A recent study by Khadem et al. (2017), showed that administration of PI3K p1108 inhibitors CAL-101 and IC87114 resulted in a decrease in parasitic burden in both a CL and VL murine model. This result was accompanied by increased cytokine production in the spleen, livers and footpads of infected mice. The authors suggest the use of these inhibitors along with amphotericin B for even better outcomes (Khadem et al., 2017).

Ibrutinib is a small inhibitor currently used for the treatment of chronic lymphocytic leukemia and other B-cell malignancies due to its action as an irreversible inhibitor of Bruton's tyrosine kinase (BTK) found on B-cells (Pan et al., 2007; Harrison, 2012). Because of its homology with BTK, IL-2 inducible kinase (ITK) found on both Th1 and Th2 cells is also inhibited by ibrutinib (Dubovsky et al., 2013). Previous studies have identified ibrutinib as a clinically relevant drug not only against cancer, but also for the treatment of infectious disease using the cutaneous model of leishmaniasis caused by $L$. major. This beneficial effect was due to a Th1 polarized response characterized by the production of disease protective cytokines such as IFN- $\gamma$ (Dubovsky et al., 2013).

Berberine chloride is a quaternary isoquinoline that acts via phosphorylation of protein $\mathrm{p} 38$ in the MAP kinase pathway. This compound upregulates NO production and IL12 expression, both disease protective, while downregulating expression of disease exacerbating IL-10 in macrophages infected with L. donovani (Saha et al., 2011). Berberine also alters AMPactivated protein kinase (AMPK) signaling, leading to increased activation of macrophage inflammasomes (Casey et al., 2015; Li et al., 2017).

Statins are HMG-CoA reductase inhibitors commonly orally administered to decrease low density lipoprotein (LDL) levels in hyperlipidemic individuals by preventing the synthesis of cholesterol in the liver (Sirtori, 2014). During $L$. donovani infection, this statin-dependent reduction in cholesterol levels resulted in decreased attachment of infectious promastigotes to macrophages, which is critical for parasite invasion. Consequently, macrophages treated with lovastatin had fewer intracellular amastigotes (Kumar et al., 2016). Furthermore, topical application of simvastatin to ear and footpad lesions of $L$. major- infected BALB/c and C57BL/6 mice reduced lesion size as well as parasitic burdens in draining lymph nodes (Parihar et al., 2016).

Naloxonazine is an opioid-receptor antagonist that upregulates expression of the vacuolar ATPase (vATPase) proton pump and actin related genes, mediating the formation and maturation of phagolysosomes. The vATPase proton pump has been shown to be critical in acidification of parasitophorous vacuoles within phagocytes. The general understanding is that promastigotes are more sensitive to acidic $\mathrm{pH}$ than amastigotes. This observation suggests that acidification of vacuole before the transformation of promastigotes into amastigotes can potentially lead to increased parasite killing (De Muylder et al., 2016).
Pentalinonsterol (cholest-4,20,24-trien-3-one) is a natural product isolated from the roots of Pentalinon andrieuxii, a native plant of the Yucatan peninsula. Recent studies have shown that Pentalinonsterol can stimulate macrophages by activating the NF-kB pathway. This activation resulted in an upregulation of $\mathrm{NO}$, critical for parasitic killing, as well as pro-inflammatory cytokines TNF- $\alpha$ and IL-12 in macrophages and bone marrow derived macrophages (BMDMs) in vitro. Pentalinonsterol treatment also increased antigen presentation and expression of costimulatory molecules, which ultimately resulted in augmentation of both the responses in vivo. Because of its immunomodulatory properties, pentalinonsterol has been proposed as a potential adjuvant in vaccination against infectious diseases (Oghumu et al., 2017).

Oleuropein is a glycosylated seco-iridoid that can be cheaply derived from numerous plants, in particular the olive tree, Olea europaea L. (Oleaceae). This natural bioactive compound was shown to promote Th1 type immune responses and increase the oxidative stress within the host, both important for protection against Leishmania infection. Balb/c mice infected with $L$. donovani and subsequently treated with oleuropein showed a Th1 polarization characterized by expression of genes like TGF- $\beta 1$ and IFN- $\gamma$ as well as transcription factors like GATA3 (Kyriazis et al., 2016). This immunomodulatory effect was believed to be due to the inhibition of IL- $1 \beta$ which promotes disease progression and non-healing phenotypes in Leishmania major infections (Voronov et al., 2010; Charmoy et al., 2016). In addition to these properties, oleuropein treatment increased the production of ROS in both in vitro and in vivo models of L. donovani infection (Kyriazis et al., 2016). Oleuropein has also been shown to inhibit extracellular signal related kinase (ERK1/2) (Abe et al., 2011). This is relevant because activation of ERK1/2 enhances expression of IL-10 and reduction of IL12 which resulted in decreased p38 MAPK activation and increased parasite survival (Feng et al., 1999; Mathur et al., 2004). Interestingly, oleuropein has stimulatory effects on the AMPK pathway similar to berberine chloride (Andreadou et al., 2014). Because of its immunomodulatory actions and low toxicity, oleuropein could be employed to complement other treatments.

Mahanine is a carbazole alkaloid isolated from a medicinal plant native to the Indian subcontinent. In vivo studies have shown that mahanine induces apoptosis of both antimony sensitive and resistant $L$. donovani (Roy et al., 2017). Mahanine augments NO and ROS generation, thereby causing parasitic apoptosis due to oxidative stress. Along with its effect on NO and ROS, mahanine affects Th1 cytokines by acting on the STAT pathway. First employed in the treatment of various types of cancer, mahanine has been effectively repurposed against VL (Roy et al., 2017). Mahanine inhibits JAK1 and Src which subsequently promotes the degradation of STAT3, an important transcription factor in macrophages that causes upregulation of IL-10 expression and suppression of Th1 responses (Biswas et al., 2011; Lee et al., 2011; Das et al., 2014). While mahanine possesses its own unique immunomodulatory effects, several other natural compounds stimulate ROS and NO production in vitro including but not limited to, lupeol from Sterculia villosa, dehydroabietic acid from Pinus elliottii, and oil extracts from 
Nectandra species (da Costa-Silva et al., 2015; Bosquiroli et al., 2017; Das et al., 2017; Goncalves et al., 2018). For example, Punica granatum, commonly known as pomegranate, has been shown to have antiparasitic and antioxidant properties (Kaur et al., 2006). A recent study has demonstrated that oral treatment with $P$. granatum juice significantly reduced the lesion sizes of mice infected with $L$. major, compared to untreated mice. The anti-leishmanial activity is attributed to the presence of flavonoid and phenolic compounds including ellagitannins and luteolin. Luteolin in particular inhibits the extracellular promastigote growth (Mittra et al., 2000). In contrast, ellagitannins enhance non-specific immunity via macrophage activation and by inducing the production of NO, IFN- $\gamma$ and TNF- $\alpha$, which increase the oxidative stress on the parasites. The study showed that $P$. granatum juice has the potential to be an effective, safe and easily administrable treatment against CL (Alkathiri et al., 2017).

Fucoidan is a multi-sulfated polysaccharide isolated from the sporophylls of the brown algae Undaria pinnatifida. Fucoidan enhances dendritic cell (DC) maturation through increased expression of MHC-II and co-stimulatory molecules such as CD80/86 and CD40 (Jin et al., 2014). Fucoidan treatment of DCs induced secretion of IL- 6 , IL-12, TNF- $\alpha$ and IFN- $\gamma$ with notable increases in NO production and decreases in production of the anti-inflammatory cytokines IL-10 and TGF- $\beta$ (Yang et al., 2008; Kar et al., 2011; Jin et al., 2014). Over 93\% inhibition of L. donovani amastigote replication was achieved in vitro and parasites were cleared from both the liver and spleen in 6 weeks in vivo; the reduction of parasite burden was observed in both antimony susceptible and resistant $L$. donovani strains (Kar et al., 2011). Fucoidan activates p38 and ERK $1 / 2$ associated NF- $\mathrm{KB}$ signaling in L. donovani-infected macrophages (Sharma et al., 2014).

Artemisinin is a natural compound found in Artemisia апnиа, a traditional Chinese medicinal herb that is the mainstay for treatment of malaria. Treatment with Artemisinin-loaded poly lactic co-glycolic acid (ALPLGA) nanoparticles was shown to increase levels of IL-2 and IFN- $\gamma$ and decrease levels of IL-4 and IL-10 in BALB/c mice infected with $L$. donovani (Want et al., 2015). Artemisinin treated macrophages secreted increased levels of IL-12 in vitro through inhibition of JNK signaling (Cho et al., 2012). Treatment of $L$. donovani-infected $\mathrm{BALB} / \mathrm{c}$ mice with artemisinin-conjugated nanoparticles and liposomal preparations resulted in approximately $80 \%$ reduction of spleen and liver parasite burdens after one administration (Want et al., 2015; Want et al., 2017). Furthermore, treatment of mice with the semi-synthetic derivative, dihydroartemisinin, has been shown to decrease the number of T-regulatory cells, which are important mediators of Leishmania pathogenesis present in the spleen, in addition to having Th1 polarizing effects (Belkaid, 2003; Noori and Hassan, 2011). Oral administration of Artemisia annua powder in gelatin capsules drastically reduced lesion size and improved appearance compared to no treatment in hamsters infected with $L$. panamensis; 5 out 6 hamsters treated with A. annua capsules daily for 30 days were completely cured and 2 clinical patients taking $A$. annua capsules were cleared of infection within 45 days without adverse reactions or reoccurrence 24 months after completion of therapy (Mesa et al., 2017).

Eugenol is a component of Syzygium aromaticum, a species of clove native of Australia and tropical regions of Central and South America. S. aromaticum has anti-bacterial, antitrypanosomal and anti-malarial activity. These properties are due to the immunomodulatory effects of this compound on both humoral and cell-mediated immune responses. Treatment of $L$. donovani-infected BALB/c mice with eugenol increased Th1 polarization, characterized by high levels of IFN- $\gamma$ and IL2 , with a concomitant decrease in the Th2 immune response (Charan Raja et al., 2017). This treatment also induced nitric oxide production in infected macrophages and proliferation of both CD4+ and CD8+ T-cells. Overall, eugenol treatment resulted in decreased parasitic burdens in the spleen and livers of L. donovani-infected mice most likely due to both leishmanicidal and immunomodulatory properties (Islamuddin et al., 2016; Charan Raja et al., 2017).

Brazilian propolis has recently been investigated for the treatment of American tegumentary leishmaniasis. Propolis is a bee product composed mainly of di-triterpens, phenolic compounds and essential oils. This natural product has previously been shown to have anti-inflammatory, anti-oxidant and immunomodulatory properties (Miranda et al., 2015). In a study from 2015, it was shown that treatment with NO in combination with Brazilian propolis mediated a decrease in number of parasitized cells, leading to reduced inflammation and tissue damage in a L. amazonensis murine model (Miranda et al., 2015). More recently, the immunomodulatory properties of Brazilian propolis was investigated in human-derived peripheral blood mononuclear cells (PBMC) isolated from L. braziliensis infected patients. This study found that in both healthy and infected donors, propolis was able to increase the levels of IL-4 and IL-17 while decreasing IL-10, showing an overall decrease in inflammation which could promote the control of the parasites (Dos Santos Thomazelli et al., 2017).

Phospholipase $\mathrm{A}_{2}\left(\mathrm{PLA}_{2}\right)$ are a family of enzymes with the function of reacting with various phospholipids to produce lysophospholipids, a class of lipid mediators, as well as arachidonic acid, a precursor of eicosanoids (Murakami and Kudo, 2002; Moreira et al., 2014). It has been previously shown that $\mathrm{PLA}_{2}$ activates NF-kB in isolated peritoneal macrophages (Moreira et al., 2014). Additionally, treatment with liposome encapsulated $\mathrm{PLA}_{2}$ isolated from the venom of Bothrops jararacussu, resulted in a significant rise in TNF- $\alpha$ and NO production in the cutaneous lesions as well as lymph nodes of L. amazonensis-infected BALB/c mice (de Barros et al., 2018).

Leptin is an adipocyte hormone that plays a role in thymic homeostasis and has been shown to mediate a pro-inflammatory response in animal models. In particular, leptin induces Th1 immune responses while suppressing Th2 responses (Maurya et al., 2016). Leptin induced Th1 polarization, characterized by IFN- $\gamma$, IL-12 and IL- $1 \beta$, resulted in decreased parasitic burdens of C57BL/6 mice infected with $L$. donovani (Dayakar et al., 2016; Maurya et al., 2016). Leptin treatment also mediated NO production in antigen-presenting cells (Maurya et al., 2016). In particular, leptin activates macrophages by promoting the 
phosphorylation of ERK1/2 and Akt, which is usually inhibited during VL infection (Dayakar et al., 2016).

MicroRNAs (miRNAs) are short, single-stranded non-coding RNAs that bind to gene transcripts to regulate protein translation (Bartel, 2009; Geraci et al., 2015). Because of their role in mediating post-transcriptional repression, miRNAs are linked to the regulation of host processes involved in the development and activity of innate and adaptive immune responses (Geraci et al., 2015; Drury et al., 2017). The immunomodulatory functions of miRNAs make them promising host targets for developing new therapeutics for infectious disease (Drury et al., 2017). miRNAs have been implicated in visceral leishmaniasis infection in macrophages and dendritic cells in vitro (Geraci et al., 2015). Additionally, certain miRNAs have been involved in T-reg specialization and stability in an L. major model, and in autophagy in both L. major and L. donovani models (Kelada et al., 2013; Frank et al., 2015; Singh et al., 2016). L. donovani infection was found to increase the stability of microRNA ribonucleoprotein (miRNP) in infected macrophages. miRNP works to restrict the production of pro-inflammatory cytokines, detrimental for parasite survival within the host cell (Chakrabarty and Bhattacharyya, 2017). For these reasons, miRNAs can serve as drug targets to manipulate the host immune response to pathogens. We summarized the compounds in this section and their targets in Table $\mathbf{1}$ and their detailed mechanism of action in Figure 1 .

\section{CHAGAS DISEASE (AMERICAN TRYPANOSOMIASIS)}

Trypanosoma cruzi is the causative agent of American trypanosomiasis (Chagas disease). This infection has a prevalence of nearly 6-8 million people worldwide (Aiga et al., 2009) and causes about 12,000 deaths annually. Although Chagas disease is endemic in certain areas in Central and South America, it is found worldwide through the migration of chronically infected individuals. Additionally, there is a low incidence of parasite-infected triatomine bugs in the lower 20 states in the United States which occasionally infect humans (Bern et al., 2011; Klotz et al., 2014).

Trypanosoma cruzi infection is most often initiated during blood feeding of parasite-infected triatomine bugs which defecate near the feeding site. Metacyclic trypomastigotes present in the insect feces enter the wound and establish infection. Metacyclic trypomastigotes are able to invade any nucleated host cells before transforming into intracellular amastigotes and replicating (Rassi et al., 2010). Amastigotes eventually differentiate into blood-stage trypomastigotes and exit the host cell. Trypomastigotes and intracellular amastigote-laden host cells disseminate within the host and can infect multiple organ systems. Key end organ tropisms for parasites are cardiac and gastrointestinal smooth-muscle. The life cycle is complete when uninfected triatomine bugs feed on infected mammalian hosts and ingest parasites, which grow and differentiate in the insect gastrointestinal tract and eventually migrate to the hindgut. The majority of Chagas infections occur through insect vector-borne transmission; however, the disease can also be transmitted transplacentally, through blood and tissue transplantation, through the consumption of parasite-laden meat or contaminated freshly squeezed fruit juice and through accidental laboratory exposure (Tyler and Engman, 2001; de Souza et al., 2010; Bern et al., 2011).

The disease has two distinct stages, acute and chronic. The acute stage lasts for 4-8 weeks and generally goes unnoticed or it presents with mild symptoms such as fever, headache, fatigue, and/or rash. Once the infection is established, most patients undergo chronic infection. Among chronically infected patients, $60-80 \%$ of individuals will develop an indeterminate chronic stage without showing any symptoms. The remaining $20-40 \%$ will eventually develop significant cardiac or gastrointestinal symptoms including arrhythmias and cardiomyopathy resulting in congestive heart failure, and gastrointestinal tract dysmotility syndromes leading to symptoms associated with achalasia, megacolon and mega-esophagus (Sanchez-Guillen Mdel et al., 2006; Bern et al., 2011).

Only two drugs available for treatment of Chagas disease are nifurtimox and benznidazole (Bern et al., 2007). These drugs are not completely effective and their use is difficult due to toxic side effects (Castro et al., 2006). Thus, there is an urgent need to develop new drugs and vaccines for the treatment and control of Chagas disease. Host-targeted therapy could provide an alternative approach to treat Chagas disease in the future. Here, we focus on some of the possible host molecular targets that can be exploited to treat Chagas disease.

\section{HOST IMMUNOLOGY}

Trypanosoma cruzi invasion of host cells, intracellular growth and parasite release eventually elicits a rise in parasitemia, which in turn induces pro-inflammatory responses by macrophages and natural killer cells and results in strong CD8 $+\mathrm{T}$ cell immune responses (Tarleton, 2015). However, these immune responses can only control the infection partially, as a low level of infection persists for the entire life of the host. During the acute phase of infection, the Th1 response is involved in protection (Tarleton et al., 2000). Driven by interleukin 2 (IL-2) and interferon gamma (IFN- $\gamma$ ) produced by Th1 cells, this type of immune response is important in resistance against $T$. cruzi infection, whereas a Th2 polarized response mediates parasite persistence. IFN$\gamma$-mediated protection is regulated by the transcription factor STAT-1 (signal transducer and activator of transcription 1), and the lack of STAT-1 has been shown to increase susceptibility to T. cruzi infection in mice (Stahl et al., 2014; Kulkarni et al., 2015).

Glycosylphosphatidylinositol (GPI)-anchored mucin-like glycoprotein from T. cruzi plays a crucial role in macrophage activation, mediating stimulation of pro-inflammatory cytokines such as TNF- $\alpha$, IL-12, and also inducing NO synthesis in innate immune cells (Camargo et al., 1997). A recent study shows that Th17, a subset of CD4+ T cells, provides a stronger protective response than Th1 cells against $T$. cruzi infection. Th17-dependent protection is due to the phagocytic respiratory burst as well as the activation of CD8+ T cells (Cai et al., 2016). 
TABLE 1 | Host-targeted therapeutics for leishmaniasis.

\begin{tabular}{|c|c|c|c|}
\hline Host-targeted Drug & Classification & Mode of action & Reference \\
\hline Imatinib & Abl/Arg kinase inhibitor & Plays a role in phagocytosis & Wetzel et al., 2012 \\
\hline $\begin{array}{l}\text { Phosphoinositide 3-kinase } \\
\gamma(\mathrm{PI} 3 \mathrm{~K} \gamma) \text { inhibitor }\end{array}$ & $\mathrm{PI} 3 \mathrm{~K} \gamma$ inhibitor & $\begin{array}{l}\text { Inhibits actin cytoskeletal } \\
\text { reorganization }\end{array}$ & Cummings et al., 2012 \\
\hline Ibrutinib & $\begin{array}{l}\text { Bruton tyrosine kinase (BTK), and } \\
\text { IL-2-inducible kinase (ITK) inhibitor }\end{array}$ & $\begin{array}{l}\text { Results in a Th1 polarized } \\
\text { immune response }\end{array}$ & Dubovsky et al., 2013 \\
\hline Berberine chloride & Hydrochloride salt & $\begin{array}{l}\text { Up-regulates nitric oxide and } \\
\text { IL-12 production while } \\
\text { downregulating IL-10 } \\
\text { production }\end{array}$ & Casey et al., 2015; Li et al., 2017 \\
\hline Statins & HMG CoA reductase inhibitors & $\begin{array}{l}\text { Leads to reduced numbers of } \\
\text { promastigotes attached to host } \\
\text { cells }\end{array}$ & Kumar et al., 2016; Parihar et al., 2016 \\
\hline Naloxonazine & Opioid receptor antagonist & $\begin{array}{l}\text { Up-regulates the expression of } \\
\text { the vacuolar ATPase (VATPase) } \\
\text { proton pump to acidify the } \\
\text { vacuole }\end{array}$ & De Muylder et al., 2016 \\
\hline Pentalinosterol & $\begin{array}{l}\text { Natural compound - cholest-4,20,24- } \\
\text { trien-3-one }\end{array}$ & $\begin{array}{l}\text { Activates macrophages to } \\
\text { up-regulate pro-inflammatory } \\
\text { cytokine and nitric oxide } \\
\text { production }\end{array}$ & Oghumu et al., 2017 \\
\hline Oleuropein & $\begin{array}{l}\text { Natural compound - glycosylated } \\
\text { seco-iridoid }\end{array}$ & $\begin{array}{l}\text { Promotes a Th1 type immune } \\
\text { response and increases } \\
\text { oxidative stress }\end{array}$ & $\begin{array}{l}\text { Voronov et al., 2010; Abe et al., 2011; } \\
\text { Charmoy et al., 2016; Kyriazis et al., } \\
2016\end{array}$ \\
\hline Mahanine & Natural compound - carbazole alkaloid & $\begin{array}{l}\text { Modulates Th1 cytokines and } \\
\text { promotes oxidative stress }\end{array}$ & $\begin{array}{l}\text { Biswas et al., 2011; Lee et al., 2011; } \\
\text { Das et al., 2014, 2017; da Costa-Silva } \\
\text { et al., 2015; Bosquiroli et al., 2017; Roy } \\
\text { et al., 2017; Goncalves et al., } 2018\end{array}$ \\
\hline $\begin{array}{l}\text { Punica granatum } \\
\text { (pomegranate) }\end{array}$ & $\begin{array}{l}\text { Natural compound - flavonoids and } \\
\text { phenolic compounds }\end{array}$ & $\begin{array}{l}\text { Activates macrophages to } \\
\text { increase oxidative stress by } \\
\text { inducing Th1 cytokines }\end{array}$ & $\begin{array}{l}\text { Kaur et al., 2006; Mittra et al., 2000; } \\
\text { Alkathiri et al., } 2017\end{array}$ \\
\hline Fucoidan & $\begin{array}{l}\text { Natural compound - multi-sulfated } \\
\text { polysaccharide }\end{array}$ & $\begin{array}{l}\text { Enhances DCs maturation and } \\
\text { stimulates production of } \\
\text { pro-inflammatory cytokines } \\
\text { while down-regulating } \\
\text { anti-inflammatory cytokines }\end{array}$ & $\begin{array}{l}\text { Yang et al., 2008; Kar et al., 2011; Jin } \\
\text { et al., 2014; Sharma et al., } 2014\end{array}$ \\
\hline Artemisinin & $\begin{array}{l}\text { Natural compound - sesquiterpene } \\
\text { lactone containing a peroxide bridge }\end{array}$ & $\begin{array}{l}\text { Increases levels of IL- } 2 \text { and } \\
\text { IFN- } \gamma \text { and decreases levels of } \\
\text { IL- } 4 \text { and IL-10 }\end{array}$ & $\begin{array}{l}\text { Belkaid, 2003; Noori and Hassan, } \\
\text { 2011; Cho et al., 2012; Want et al., } \\
\text { 2015, } 2017\end{array}$ \\
\hline Eugenol & Natural compound - phenylpropene & $\begin{array}{l}\text { Mediates Th1 polarized } \\
\text { response }\end{array}$ & $\begin{array}{l}\text { Islamuddin et al., 2016; Charan Raja } \\
\text { et al., } 2017\end{array}$ \\
\hline Propolis & $\begin{array}{l}\text { Natural compound - mainly flavonoids, } \\
\text { aromatic acids and benzopyranes }\end{array}$ & Decreases inflammation & $\begin{array}{l}\text { Miranda et al., 2015; Dos Santos } \\
\text { Thomazelli et al., } 2017\end{array}$ \\
\hline Phospholipase $A_{2}$ & Enzyme that produces lipid mediators & $\begin{array}{l}\text { Promotes activation of NF-kB in } \\
\text { macrophages and results in } \\
\text { increased nitric oxide and } \\
\text { TNF- } \alpha \text { production }\end{array}$ & $\begin{array}{l}\text { Murakami and Kudo, 2002; Moreira } \\
\text { et al., 2014; de Barros et al., } 2018\end{array}$ \\
\hline Leptin & Adipocyte hormone & $\begin{array}{l}\text { Induces a Th1 polarized } \\
\text { response and augments nitric } \\
\text { oxide production }\end{array}$ & $\begin{array}{l}\text { Dayakar et al., 2016; Maurya et al., } \\
2016\end{array}$ \\
\hline Micro RNA targets (miRNA) & mRNA & Act as immunomodulators & $\begin{array}{l}\text { Bartel, 2009; Kelada et al., 2013; Frank } \\
\text { et al., 2015; Geraci et al., } 2015\end{array}$ \\
\hline
\end{tabular}

Thus, the combined effect of cell-mediated immune unbalanced response associated continuous subpatent parasite antigens may play a significant role in the development of the pathogenesis of Chagas disease. Therefore, host-directed drugs modulating host immune response could be a viable therapeutics for managing Chagas disease.

\section{HOST-TARGETED THERAPEUTICS AND APPROACHES FOR TREATMENT OF CHAGAS DISEASE}

While host-targeted therapy in T. cruzi infection has not been well studied, there are several studies that show different host 


\section{Host-targeted therapy in Leishmania infection}

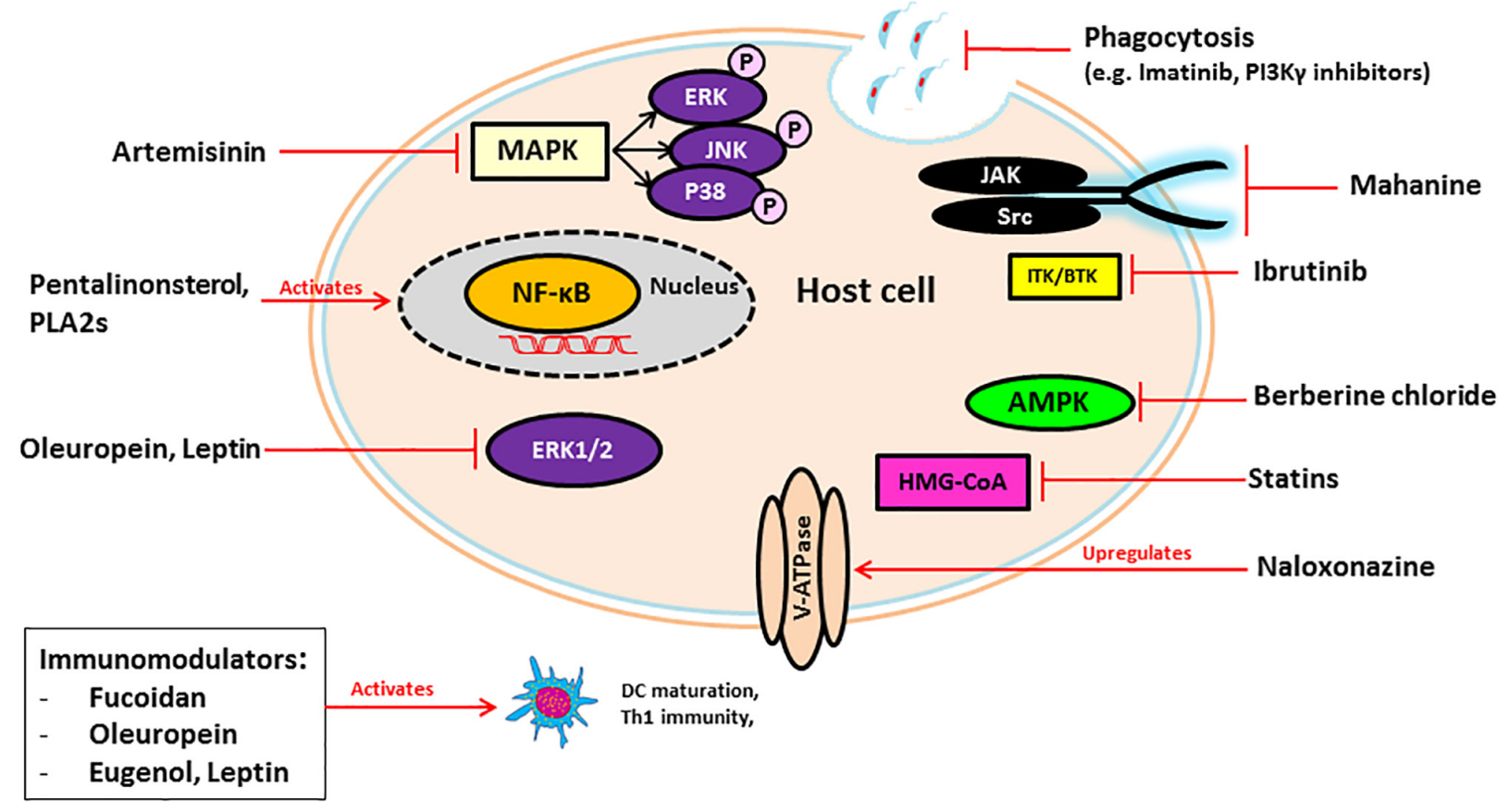

FIGURE 1 | Schematic diagram of mechanisms of host-targeting against Leishmania infection.

molecules are critical for the establishment of T. cruzi infection, and the inhibition of these molecules may reduce or ablate infection.

G-protein coupled receptors are a family of receptors that utilize G-proteins to transduce signals into the cell and control diverse functions, including regulation of gene transcription, cellular motility, and metabolic enzymes. T. cruzi trypomastigotes invade host cells through association with various GPCRs including platelet-activating factor receptor (Kawano et al., 2011), bradykinin receptor B1 and B2 (Scharfstein et al., 2000; Todorov et al., 2003) and muscarinergic 2 receptor (Wallukat et al., 2010). Several inhibitors of GPCRs have been shown to prevent $T$. cruzi entry and infection and mediate protection against Chagas disease. Cannabinoids, a family of potent immunosuppressive agents, inhibit G-protein signaling and invasion of cardiac myoblasts by T. cruzi in mice (Croxford et al., 2005). It is known that parasite-derived thromboxane A2 (TXA2) is important for disease progression in Chagas disease (Villalta et al., 2009). Intracellular amastigotes release TXA2 and initiate signaling after binding with TXA2 receptor (TP). Binding of TXA2 and TP activates a variety of cell types including dendritic cells, monocytes, platelets, cardiac myocytes and endothelial cells, resulting in apoptosis of cells, vasoconstriction, dilated cardiomyopathy, enhanced platelet adherence and aggregation (Ashton et al., 2007). The TXA2 receptor antagonist SQ29548 has been shown to inhibit T. cruzi infection mediated through TP (Ashton et al., 2007; Silva et al., 2016).
Carvedilol is a non-selective $\beta$-adrenergic receptor blocker used to manage congestive heart failure. It has been shown to improve Chagas cardiomyopathy in combination with reninangiotensin inhibitors (Botoni et al., 2007).

SB-431542 compound is an inhibitor of the TGF- $\beta$ type I receptor kinase. It has been shown that host TGF- $\beta$ is increased during T. cruzi infection (Silva et al., 1991) and is taken up by amastigotes to modulate the life cycle of T. cruzi (AraujoJorge et al., 2002; Waghabi et al., 2005). Recently, it has been reported that elevated TGF- $\beta$ causes the heart fibrosis and severe cardiomyopathy in Chagas disease. These findings suggest that the treatment of cardiomyocytes with SB-431542, can inhibit the effect of TGF- $\beta$-mediated amastigote proliferation and cardiac myopathy in Chagas disease. Experimental evidence suggests that treatment with this drug lowers the penetration of trypomastigotes into cardiomyocytes, decreases intracellular amastigote multiplication and trypomastigote release from the cells, reducing the severity of infection and mortality of mice (Waghabi et al., 2007, 2009).

Terpenoides possess anti-trypanosomal activity. Treatment with terpenoid compounds, such as cumanin and psilostachyin, reduces parasitemia and mortality of parasite-infected mice and intracellular amastigote replication in Vero cells (Sulsen et al., 2013). Terpenoides are a widespread group of natural products and potent inhibitors of NF- $\mathrm{B}$ signaling which mediates TNF$\alpha$-induced cell death. During early stages of infection, T. cruzi invade hepatocytes, macrophages, and Kupffer cells and increase TNF- $\alpha$ production that causes apoptotic cell death of infected 
hepatocytes (Ronco et al., 2010). Furthermore, infection of $T$. cruzi leads to activation of host cell NF- $\kappa B$ signaling that protects infected cells from undergoing apoptosis (Petersen et al., 2006). As terpenoides are such potent inhibitors of $\mathrm{NF}-\kappa \mathrm{B}$, treatment might result in robust apoptotic cell death of infected cells that release intracellular parasites outside of the cells. Although the exact mechanism of the trypanocidal effect of terpenoides is still unknown, they may target released parasites from apoptotic host cells directly and engage in antitrypanosomal activity. In contrast, da Silva et al. (2013) showed that the sesquiterpene lactones-psilostachyin and cynaropicrin did not have efficacy in the mouse model of acute T. cruzi infection when comparing benznidazole (da Silva et al., 2013).

Immuno-modulators are compounds that modify immune responses. Extracts from Lycopodium clavatum, a spore bearing vascular plant, act as an immuno-modulator to induce Th1 immune responses. T. cruzi infected rats treated with Lycopodium clavatum extract have reduced progression of GI tract Chagas disease (Brustolin Aleixo et al., 2017). A recent study by Otta et al. (2018) showed that K777 the extract lead compound induces prominent proinflammatory responses modulation by interleukin -10 -positive $\mathrm{CD} 4^{+} / \mathrm{CD} 8^{+}$ $\mathrm{T}$ cells and this contributed to the protection against the Chagas disease. In addition, diet supplementation with fish oil led to increase the resistance to $T$. cruzi infection through modulating various immunological factors (Lovo-Martins et al., 2017).

Inhibition of $\beta$-oxidation: The replication of intracellular amastigotes is largely supported by parasite scavenging of host metabolic network, including host cell fatty acid metabolism in cardiac and smooth muscle (Combs et al., 2005). It has been shown that long chain fatty acid oxidation is the key source of nutrients for intracellular amastigotes. Long chain fatty acids are oxidized in the peroxisome to produce short chain fatty acids that are transported to the mitochondria by acylCoA dehydrogenase for $\beta$-oxidation. Recent study of siRNA screen shows that the enzymes of $\beta$-oxidation are essential for growth of amastigotes inside the host cells and alteration of fatty acid metabolism and $\beta$-oxidation inhibits the intracellular growth of amastigotes (Caradonna et al., 2013). Although several $\beta$-oxidation inhibitors have been identified as, for example etomoxir (Paumen et al., 1997), mildronate (Liepinsh et al., 2006), trimetazidine, and ranolazine (Sabbah and Stanley, 2002), more studies are needed to find which can treat Chagas disease. We summarized the compounds in this section and their targets in Table 2 and their detailed mechanism of action in Figure 2.

\section{HUMAN AFRICAN TRYPANOSOMIASIS (SLEEPING SICKNESS)}

Human African trypanosomiasis (HAT) is caused by two subspecies of Trypanosoma brucei, T. b. gambiense, and T. $b$. rhodesiense. T. $b$. gambiense is the causative agent of a chronic form of the disease often referred to as West African trypanosomiasis, which is prevalent in Western and Central
Africa and affects 24 countries. T. $b$. rhodesiense causes a more acute form of the disease found in Eastern and Southern Africa affecting 13 countries, and is often referred to as East African trypanosomiasis (Franco et al., 2014).

Of the two subspecies, T. b. gambiense is the more prevalent threat, as humans are considered the primary reservoir for the parasite. T. $b$. rhodesiense primarily infects animal reservoirs, and humans are incidentally infected (Franco et al., 2014). According to the World Health Organization (WHO), the majority of approximately 2,000 new cases of Western African trypanosomiasis reported in 2016 were in the Congo, while only about 50 new cases were found in Eastern Africa (World Health Organization, 2017). Currently, there are estimated to be fewer than 20,000 active cases of sleeping sickness, with 65 million at risk. The majority of new cases occur in the Democratic Republic of Congo, contributing 84\% of new cases in 2015 (Franco et al., 2014). HAT is slated for elimination as a public health threat in 2020 , with a downward trend in new cases and a drop of yearly DALY from 2,734 DALY in the year 2000 to a DALY of 372 in year 2015 (World Health Organization, 2013, 2016, 2017).

Both subspecies of $T$. brucei are transmitted by Tsetse flies harboring metacyclic trypomastigotes, while feeding on mammalian hosts. Once inside the host, trypomastigotes migrate to the blood stream and lymphatics disseminate throughout the host, at which point they begin to multiply through binary fission. (Centers for Disease Control and Prevention, 2016). In acute human trypanosomiasis, parasites disseminate throughout the lymphatics and blood stream of the host. Parasites eventually breach the blood-brain barrier, leading to infection of the central nervous system, and eventual death in essentially $100 \%$ of untreated patients (Brun et al., 2010).

\section{HOST IMMUNOLOGY}

Upon entering the human host, metacyclic T. brucei immediately encounter the host's innate immune defense mechanisms. These parasites, however, are covered in a thick, highly dense coat of variable surface glycoproteins (VSGs) which protect parasites from the mounting host humoral response, as well as from host complement-mediated lysis (Horn, 2014). Parasites undergo switching of antigenically different VSGs in order to circumvent antibody-mediated killing. This switching of VSGs results in undulating waves of parasitemia in which parasites possessing older VSG coats are subject to immune clearance and clones expressing neo-VSG escape immune surveillance and replicate. This mechanism allows the trypanosomes to replicate and survive at sub-lethal levels of infection.

Human susceptibility, disease progression and outcome of HAT are linked to differences in individual genetic predisposition for varying cytokine levels and $\mathrm{T}$ cell differentiation. Once infected, certain individuals can control infection and become asymptomatic carriers without any specific intervention. These asymptomatic people have increased quantities of IL-6, IL-8 and TNF $\alpha$, as well as decreased levels of IL-12, indicating that the ability to control infection relies upon a controlled Th1 response. However, those individuals showing high levels of 
TABLE 2 | Host-targeted therapeutics for Chagas disease.

\begin{tabular}{|c|c|c|c|}
\hline Host-targeted Drug & Classification & Mode of action & Reference \\
\hline Cannabinoids, SQ29548 & inhibitors & G protein couple receptor & $\begin{array}{l}\text { Scharfstein et al., 2000; Todorov et al., 2003; } \\
\text { Croxford et al., 2005; Ashton et al., 2007; } \\
\text { Wallukat et al., 2010; Kawano et al., } 2011\end{array}$ \\
\hline Carvedilol & $\beta$-adrenergic receptor blocker & $\beta$-adrenergic receptor & Botoni et al., 2007 \\
\hline SB-431542 compound & inhibitor & TGF- $\beta$ type I receptor kinase & $\begin{array}{l}\text { Silva et al., 1991; Araujo-Jorge et al., 2002; } \\
\text { Waghabi et al., 2005; Waghabi et al., } 2007\end{array}$ \\
\hline Terpenoides & Inhibitors & $N F-\kappa B$ signaling & $\begin{array}{l}\text { Petersen et al., 2006; Ronco et al., 2010; da } \\
\text { Silva et al., 2013; Sulsen et al., } 2013\end{array}$ \\
\hline Lycopodium clavatum & immunomodulator & $\begin{array}{l}\text { Induces Th1 immune } \\
\text { responses }\end{array}$ & $\begin{array}{l}\text { Brustolin Aleixo et al., 2017; Lovo-Martins et al., } \\
\text { 2017; Otta et al., } 2018\end{array}$ \\
\hline
\end{tabular}

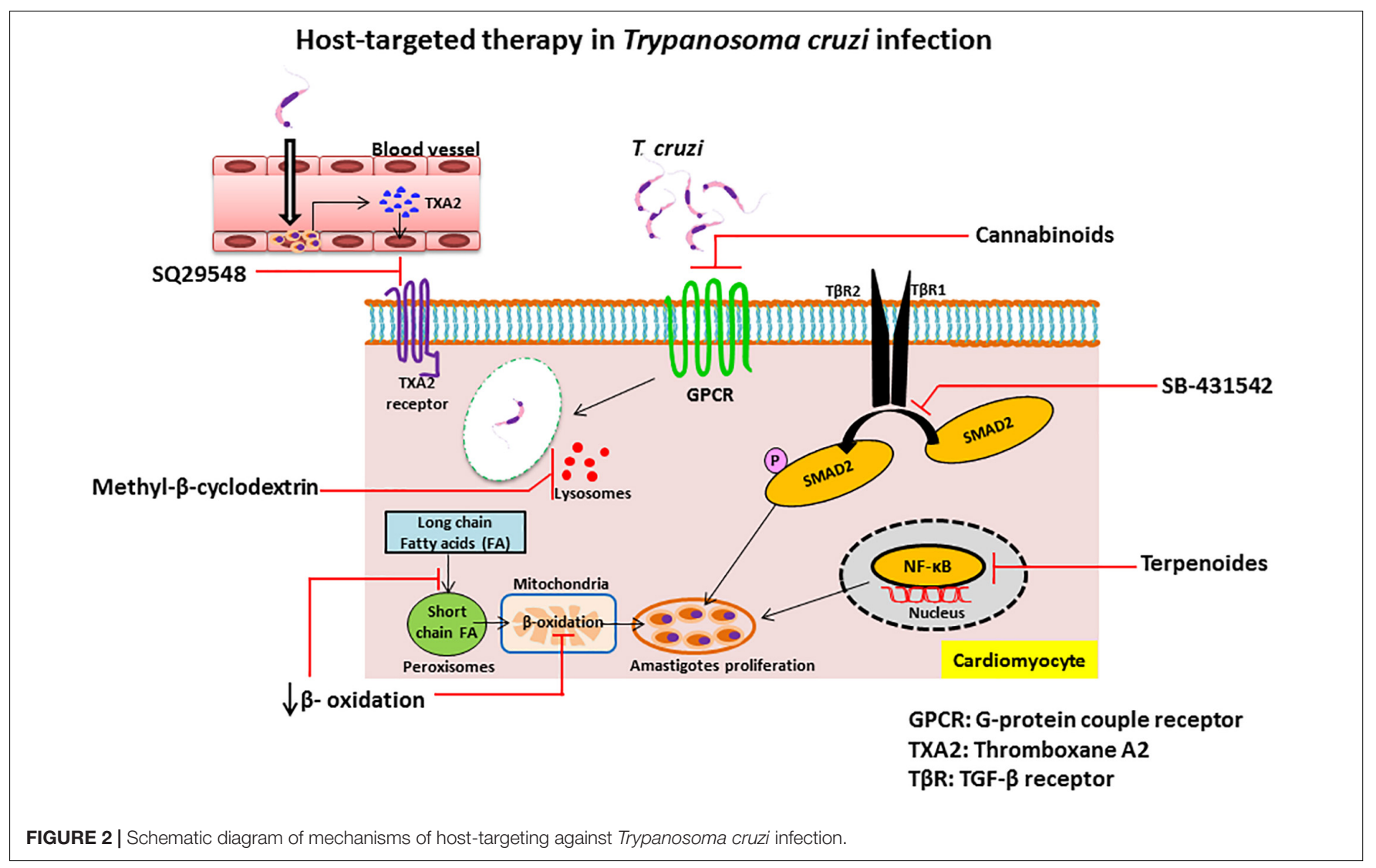

IL-6, IL-8, TNF $\alpha$, and IL-10 are at risk of developing disease once infected (Courtin et al., 2006; Kato et al., 2015, 2016). In contrast, the individuals who show more susceptibility to uncontrolled infection produce higher amounts of IL-2 and IL4. Control of late infection once it has been established, relies upon the immune system being able to effectively switch from a Th1 to a Th2 immune response (Ilboudo et al., 2014). While the Th1 response is more beneficial during the initial stages of infection, more anti-inflammatory $\mathrm{Th} 2$ responses are implicated in trypano-tolerance once an infection has been established. IFN$\gamma$ expression is responsible for early resistance and control against initial infection (Hertz et al., 1998). While IFN- $\gamma$ is beneficial to the host during initial stages of infection, the lack of effective switching to a more polarized Th2 response during the late stages of infection may lead to hyper-inflammation in the CNS, ultimately overwhelming the host (Shi et al., 2003).

In addition to the Th1 and Th2 response, high concentrations of VSG released by the parasites in the blood stream play an important role in inducing host immune response. Glycosylphosphatidyl-inositol (GPI)-phospholipase C induced release of GPI-linked VSGs exposes macrophages to previously masked regions of the GPI-tails of VSG. GPI-recognition by macrophages induces MyD88 dependent activation of the NF- $\kappa \mathrm{B}$ cascade resulting in a massive release of TNF- $\alpha$, IL-1, and IL12 (Leppert et al., 2007; Cheung et al., 2016; Stijlemans et al., 2016). This release of pro-inflammatory cytokines alongside parasite components results in the induction of classically activated macrophages. These macrophages release ROS and 
NO which can be detrimental to parasites, however, they are also damaging to the host, causing physiological and cellular destruction (Stijlemans et al., 2016).

\section{HOST-TARGETED THERAPEUTICS AND APPROACHES FOR TREATMENT OF HAT}

Current treatment approaches of HAT consist of 5 drugs, each one specific for different stages of the infection. Pentamidine and suramin are used to treat the first stage of the disease, whereas melarsoprol and a combination of nifurtimox-eflornithine are employed to treat the second stage of the disease. All these drugs have significant potential side effects. Pentamidine treatment is fairly ineffective in combating the second stage of infection by $T$. b. gambiense and both stages of $T$. $b$. rhodesiense, suramin treatment is only effective against the first stage of $T$. $b$. rhodesiense infection (Buscher et al., 2017).

Melarsoprol is employed to treat the late-stage of infections caused by both T. b. gambiense and T. b. rhodesiense, and is the only drug used for late-stage infection caused by $T$. $b$. rhodesiense. However, significant toxicity, the mode of administration and the lack of its availability in endemic areas, hinder widespread usage of this drug. Although nifurtimox and eflornithine are individually effective against $T . b$. gambiense infection, combination therapy with these drugs has better efficacy and diminished side effects (Barrett et al., 2007; Priotto et al., 2009; Babokhov et al., 2013).

There are currently three drugs under development for HAT, as well as a few host target molecules which have shown promising results in the reduction of parasitemia.
Diamidine derivatives, including pafuramidine (DB289), which is administered orally, is well tolerated and mediates parasite clearance in late-stage infections of both human T. brucei subspecies. However, after stage III clinical trials, DB289 was abandoned due to high nephrotoxicity. Despite this, DB289 has spurred the development of other diamidine derivative drugs (Kennedy, 2013).

Benzoxaborole drugs, such as SCYX-7158, are capable of crossing the blood-brain barrier in vivo and can clear infection of both $T$. brucei subspecies. This drug can be administered orally and also has a long half-life, allowing it to be used as a single dose. SCYX-7158 successfully completed stage I clinical trials and has been approved to move forward with stage II/III clinical trials (Jacobs et al., 2011). While no specific proteins or enzyme have yet been shown to play a role in the method of action of benzoxaboroles, evidence strongly suggests that drugs impede upon the ability of $T$. brucei to properly metabolize methionine (Steketee et al., 2018).

Fexinidazole, a nitroimidazole compound which is effective against both parasites and CNS disease, is safe and well tolerated in early studies. A recent study by Mesu et al. (2018), has reported that stage II/III clinical trials of fexinidazole against HAT have been completed and showed that oral fexinidazole is effective and safe for the treatment of $T$. $b$. gambiense infection compared with nifurtomox-eflornithine combination therapy in late-stage HAT patients. No method of action for nitroimidazoles has yet been elucidated, though it is known to be a substrate for a type I nitro-reductase and is theorized to function in vivo as a pro-drug (Wyllie et al., 2016; Papadopoulou et al., 2017).

Tyrosine kinase inhibitors, such as lapatinib and a few of its derivatives have shown some activity in controlling T. brucei

TABLE 3 | Host-targeted and anti-parasitic therapeutics for HAT.

\begin{tabular}{|c|c|c|c|}
\hline Host-targeted drug & Classification & Mode of action & Reference \\
\hline Acoziborole (SCYX-7158) & Benzoxaborole drug & $\begin{array}{l}\text { Negatively impacts methionine } \\
\text { metabolism }\end{array}$ & Jacobs et al., 2011; Steketee et al., 2018 \\
\hline Fexinidazole & Nitroimidazole compound & $\begin{array}{l}\text { Nitroreductase substrate } \\
\text { pro-drug }\end{array}$ & $\begin{array}{l}\text { Wyllie et al., 2016; Papadopoulou et al., 2017; } \\
\text { Mesu et al., } 2018\end{array}$ \\
\hline Lapatinib & Kinase Inhibitor & TbLBPK 1-4 inhibition & Guyett et al., 2017 \\
\hline S-(2-boronoethyl)-L-cysteine (BEC) & Arginase inhibitor & $\begin{array}{l}\text { Reduction in quantity of growth } \\
\text { factors available for } \\
\text { trypanosomes }\end{array}$ & $\begin{array}{l}\text { Nzoumbou-Boko et al., 2017; Onyilagha et al., } \\
2018\end{array}$ \\
\hline Curcumin, gallic acid, quercetin, resveratrol & $\begin{array}{l}\text { Phenolic or flavonoid } \\
\text { compounds }\end{array}$ & $\begin{array}{l}\text { Increases oxidative stress } \\
\text { against the parasites, while } \\
\text { offering oxidative protection } \\
\text { against the host }\end{array}$ & $\begin{array}{l}\text { Wolkmer et al., 2013; Smith et al., 2016; Baldim } \\
\text { et al., } 2017\end{array}$ \\
\hline Naphthyridine derivatives, thiosemicarbazone & Chelating compounds & $\begin{array}{l}\text { Antioxidant and } \\
\text { anti-inflammatory properties, } \\
\text { transition metal chelation }\end{array}$ & Ellis et al., 2015; Wall et al., 2018 \\
\hline
\end{tabular}


infection (Behera et al., 2014; Woodring et al., 2015). Lapatanib mediates antiparasitic activity against trypanosomes by inhibiting four separate protein kinases leading to changes in flagellar topology and an inhibition in the parasite endocytosis. These four kinases have been termed TbLBPK 1-4 and their interruption results in the dephosphorylation of BILBO-1, kinesins, and Rab in T. brucei (Guyett et al., 2017).

$\mathrm{PI} 3 \mathrm{~K} / \mathrm{mTOR}$ inhibitors, such as NVP-BEZ235 have efficacy in combating T. brucei infection using a mouse model (DiazGonzalez et al., 2011). Through inhibition of several kinase cascades necessary for bloodstream trypanosomes to thrive, effects are seen in the stability of parasite flagellum, in the ability of trypanosomes to mount a proper stress response to complement-mediated and osmotic-lysis, and in endocytosis (Seixas et al., 2014; Fernandez-Cortes et al., 2017).

Arginase Inhibitors, namely $S$-(2-boronoethyl)-L-cysteine (BEC), have been shown to reduce the parasitic burden both in vivo and in vitro. By blocking Arginase-1 and reducing available growth factors released by macrophages, proliferation of parasites is reduced. $\mathrm{TbKHCl}$ has also been identified as a candidate protein involved with this immunomodulation (Nzoumbou-Boko et al., 2017). Furthermore, it has been shown that preventing the function of Arginase-1 results in the prevention of myeloid-derived suppressor cells inhibiting $\mathrm{CD} 4{ }^{+}$ T-cell proliferation, as well as the production of IFN- $\gamma$, both of which aid in suppression of trypanosomes (Onyilagha et al., 2018).

Phenolic or flavonoid compounds are a group of plant derived antioxidants which have shown some trypanocidal effects in vitro and include the compounds curcumin, gallic acid, quercetin, and resveratrol. Curcumin in particular has been shown to have immunomodulatory effects on the host, preventing damage caused by the generation of ROS (Wolkmer et al., 2013). Gallic acid and quercetin both have also been shown to have prooxidant effects, leading to a direct trypanocidal effects by generation of excess ROS while also maintaining the host protective antioxidant effects (Baldim et al., 2017). Several of these compounds have also been identified as having inhibitory effects against T. brucei RNA triphosphatase (Smith et al., 2016). Few in vivo studies have been carried out in relation to these plant derived phenolic or flavonoid antioxidant compounds, making this a target area of interest for future research.

Antioxidant vitamins, in particular vitamin C, but also vitamins $\mathrm{E}$ and $\mathrm{A}$, have protective effects for the host during T. brucei infection through in vivo studies. These vitamins are presumed to function as antioxidant to reduce parasitemia and largely reduce organ damage associated with $T$. brucei infections (Ibrahim et al., 2016). Furthermore, vitamin $\mathrm{C}$ has been shown to potentiate the trypanocidal effects of diminazene aceturate in a co-administration trial (Chekwube et al., 2014). More recently, vitamin D3 has shown some efficacy in protecting the host during T. brucei infection, however the mechanism of action is not yet known (Jamal et al., 2016).

Chelating compounds have myriad positive effects for the host including anti-inflammatory and antioxidant properties. 1,8-naphthyridine derivative compounds are particularly of interest, as they have been shown to possess anti-trypanosomal activity via their ability to chelate $\mathrm{Zn}^{2+}, \mathrm{Cu}^{2+}$ and $\mathrm{Fe}^{2+}$ which are necessary for trypanosomes to thrive in the host (Wall et al., 2018). Thiosemicarbazone has also shown to have some efficacy in ridding a host of trypanosomes through chelation of iron (Ellis et al., 2015).

Presently, no host-targeted drugs or vaccines are described for the treatment or prevention of HAT. The presence of VSGs and the parasites' ability to undergo antigenic variation represent a major challenge for vaccine discovery and unfortunately there has been no development of drugs to target the VSG gene switching mechanism. Potential host-targeting drugs include those affecting host immunomodulation and those which can affect a polarized shift toward a Th1 response, while increasing the production of IFN- $\gamma$ to drive the clearance of the parasites before they are able to invade the CNS. We summarized the compounds in this section and their targets in Table 3.

\section{CONCLUSION}

Leishmaniasis, Chagas disease and HAT cause the highest number of deaths amongst all NTDs (Hotez et al., 2007). One of the major confounding issues to eliminating these NTDs is that they are often present in small endemic areas; they have relatively limited global disease burdens and are effectively ignored by the community at large. This is further compounded in that these endemic areas are often subject to political and military turmoil, in areas which lack infrastructural support or effective health care systems. Finally, climate change has also had an impact on the spread of NTDs, as the warmer weather increases the development of insect vectors, which escalates the transmission of these diseases (Hotez, 2017).

Because these infections are difficult to eradicate, it is imperative that more attention is directed toward finding preventive and curative therapeutics to control their spread. There are currently no prophylactic vaccines for the abovementioned protozoan diseases and the available treatments are antiquated and have significant toxicities. Development of novel agents or utilization of existing host-targeted therapeutics is a promising avenue for the treatment of protozoan NTDs. Despite the numerous advances in the immunology and cell biology fields, we are still far from eradicating these diseases. We believe that moving forward it will be crucial to allocate more funds toward pre-clinical and especially clinical research focused on developing and testing new host-targeted therapeutics for NTDs. Unfortunately, many NTDs affect remote and rural areas of low-and middle income countries (LMICs) with limited resources, infrastructures, and medical personnel. In these areas it is challenging to follow the Good Clinical Practices (GCPs) outlined by WHO and International Conference of Harmonization (ICH) to conduct meaningful clinical trials (Boelaert and Consortium, 2016; Ravinetto et al., 2016). We hope that raising awareness about NTDs and their burden will fuel the already ongoing mobilization of resources on a global scale to aid the development of more infrastructures to conduct 
clinical trials as well as screening and treatment in endemic areas.

\section{AUTHOR CONTRIBUTIONS}

$\mathrm{SV}, \mathrm{BJ}, \mathrm{GV}, \mathrm{NR}, \mathrm{GH}$, and $\mathrm{OH}$ reviewed the literature and wrote sections and first draft of the manuscript. AS and BM contributed to conception of the manuscript, wrote sections of the manuscript

\section{REFERENCES}

Abe, R., Beckett, J., Abe, R., Nixon, A., Rochier, A., Yamashita, N., et al. (2011). Olive oil polyphenol oleuropein inhibits smooth muscle cell proliferation. Eur. J. Vasc. Endovasc. Surg. 41, 814-820. doi: 10.1016/j.ejvs.2010.12.021

Aiga, H., Aragon, H. R., Zuniga, C., Montoya, M. V., Bolanos, F. J., and Who, E. C. (2009). Donor agency commitment to Chagas disease. Lancet 373, 2024-2025. doi: 10.1016/S0140-6736(09)61109-0

Alexander, J., Carter, K. C., Al-Fasi, N., Satoskar, A., and Brombacher, F. (2000). Endogenous IL-4 is necessary for effective drug therapy against visceral leishmaniasis. Eur. J. Immunol. 30, 2935-2943. doi: 10.1002/1521-4141(200010) 30:10<2935::AID-IMMU2935>3.0.CO;2-Q

Alkathiri, B., El-Khadragy, M. F., Metwally, D. M., Al-Olayan, E. M., Bakhrebah, M. A., and Abdel Moneim, A. E. (2017). Pomegranate (Punica granatum) juice shows antioxidant activity against cutaneous leishmaniasis-induced oxidative stress in female BALB/c mice. Int. J. Environ. Res. Public Health 14:E1592. doi: 10.3390/ijerph14121592

Andreadou, I., Mikros, E., Ioannidis, K., Sigala, F., Naka, K., Kostidis, S., et al. (2014). Oleuropein prevents doxorubicin-induced cardiomyopathy interfering with signaling molecules and cardiomyocyte metabolism. J. Mol. Cell Cardiol. 69, 4-16. doi: 10.1016/j.yjmcc.2014.01.007

Araujo-Jorge, T. C., Waghabi, M. C., Hasslocher-Moreno, A. M., Xavier, S. S., Higuchi Mde, L., Keramidas, M., et al. (2002). Implication of transforming growth factor-betal in Chagas disease myocardiopathy. J. Infect. Dis. 186, 1823-1828. doi: 10.1086/345882

Ashton, A. W., Mukherjee, S., Nagajyothi, F. N., Huang, H., Braunstein, V. L., Desruisseaux, M. S., et al. (2007). Thromboxane A2 is a key regulator of pathogenesis during Trypanosoma cruzi infection. J. Exp. Med. 204, 929-940. doi: $10.1084 /$ jem.20062432

Babokhov, P., Sanyaolu, A. O., Oyibo, W. A., Fagbenro-Beyioku, A. F., and Iriemenam, N. C. (2013). A current analysis of chemotherapy strategies for the treatment of human African trypanosomiasis. Pathog. Glob. Health 107, 242-252. doi: 10.1179/2047773213Y.0000000105

Baldim, J. L., de Alcantara, B. G. V., Domingos, O. D. S., Soares, M. G., Caldas, I. S., Novaes, R. D., et al. (2017). The correlation between chemical structures and antioxidant, prooxidant, and antitrypanosomatid properties of flavonoids. Oxid. Med. Cell. Longev. 2017:3789856. doi: 10.1155/2017/3789856

Barrett, M. P., Boykin, D. W., Brun, R., and Tidwell, R. R. (2007). Human African trypanosomiasis: pharmacological re-engagement with a neglected disease. $\mathrm{Br}$. J. Pharmacol. 152, 1155-1171. doi: 10.1038/sj.bjp.0707354

Bartel, D. P. (2009). MicroRNAs: target recognition and regulatory functions. Cell 136, 215-233. doi: 10.1016/j.cell.2009.01.002

Behera, R., Thomas, S. M., and Mensa-Wilmot, K. (2014). New chemical scaffolds for human african trypanosomiasis lead discovery from a screen of tyrosine kinase inhibitor drugs. Antimicrob. Agents Chemother. 58, 2202-2210. doi: 10.1128/AAC.01691-13

Belkaid, Y. (2003). The role of CD4 $(+)$ CD25 $(+)$ regulatory T cells in Leishmania infection. Expert Opin. Biol. Ther. 3, 875-885. doi: 10.1517/14712598.3. 6.875

Bermudez, J., Davies, C., Simonazzi, A., Real, J. P., and Palma, S. (2016). Current drug therapy and pharmaceutical challenges for Chagas disease. Acta Trop. 156, 1-16. doi: 10.1016/j.actatropica.2015.12.017

Bern, C., Kjos, S., Yabsley, M. J., and Montgomery, S. P. (2011). Trypanosoma cruzi and Chagas' Disease in the United States. Clin. Microbiol. Rev. 24, 655-681. doi: 10.1128/CMR.00005-11 and revised the manuscript. All authors read and approved the submitted version.

\section{FUNDING}

We would like to acknowledge the following grant support NIH (AI130485), NIH (AI138555), and DOD (W81XWH-14-2-0169). This work was supported by NIH grant (AI131227) to BM.

Bern, C., Montgomery, S. P., Herwaldt, B. L., Rassi, A. Jr., Marin-Neto, J. A., Dantas, R. O., et al. (2007). Evaluation and treatment of Chagas disease in the United States: a systematic review. JAMA 298, 2171-2181. doi: 10.1001/jama. 298.18.2171

Bidri, M., Vouldoukis, I., Mossalayi, M. D., Debre, P., Guillosson, J. J., Mazier, D., et al. (1997). Evidence for direct interaction between mast cells and Leishmania parasites. Parasite Immunol. 19, 475-483. doi: 10.1046/j.1365-3024.1997.d01153.x

Biswas, A., Bhattacharya, A., Kar, S., and Das, P. K. (2011). Expression of IL-10triggered STAT3-dependent IL-4Ralpha is required for induction of arginase 1 in visceral leishmaniasis. Eur. J. Immunol. 41, 992-1003. doi: 10.1002/eji. 201040940

Boelaert, M., and Consortium, N. (2016). Clinical research on neglected tropical diseases: challenges and solutions. PLoS Negl. Trop. Dis. 10:e0004853. doi: 10.1371/journal.pntd.0004853

Bosquiroli, L. S. S., Dos Santos Ferreira, A. C., Farias, K. S., da Costa, E. C., Matos, M. F. C., Kadri, M. C. T., et al. (2017). In Vitro antileishmania activity of sesquiterpene-rich essential oils from Nectandra species. Pharm. Biol. 55, 2285-2291. doi: 10.1080/13880209.2017.1407803

Botoni, F. A., Poole-Wilson, P. A., Ribeiro, A. L., Okonko, D. O., Oliveira, B. M., Pinto, A. S., et al. (2007). A randomized trial of carvedilol after reninangiotensin system inhibition in chronic Chagas cardiomyopathy. Am. Heart. J 153, 544.e1-588.e1. doi: 10.1016/j.ahj.2006.12.017

Bray, P. G., Barrett, M. P., Ward, S. A., and de Koning, H. P. (2003). Pentamidine uptake and resistance in pathogenic protozoa: past, present and future. Trends Parasitol. 19, 232-239. doi: 10.1016/S1471-4922(03)00069-2

Brun, R., Blum, J., Chappuis, F., and Burri, C. (2010). Human African trypanosomiasis. Lancet $375, \quad 148-159$. doi: 10.1016/S0140-6736(09) 60829-1

Brustolin Aleixo, C. F., Ferraz, F. N., Massini, P. F., Lopes, C. R., Falkowski Temporini, G. J., Aleixo, D. L., et al. (2017). Beneficial immunomodulatory and neuro digestive effect in Trypanosoma cruzi infection after Lycopodium clavatum 13c treatment. Microb. Pathog. 112, 1-4. doi: 10.1016/j.micpath.2017. 09.026

Buscher, P., Cecchi, G., Jamonneau, V., and Priotto, G. (2017). Human African trypanosomiasis. Lancet 390, 2397-2409. doi: 10.1016/S0140-6736(17)31510-6

Cai, C. W., Blase, J. R., Zhang, X., Eickhoff, C. S., and Hoft, D. F. (2016). Th17 cells are more protective than Th1 cells against the intracellular parasite Trypanosoma cruzi. PLoS Pathog. 12:e1005902. doi: 10.1371/journal.ppat. 1005902

Camargo, M. M., Almeida, I. C., Pereira, M. E., Ferguson, M. A., Travassos, L. R., and Gazzinelli, R. T. (1997). Glycosylphosphatidylinositol-anchored mucinlike glycoproteins isolated from Trypanosoma cruzi trypomastigotes initiate the synthesis of proinflammatory cytokines by macrophages. J. Immunol. 158, 5890-5901.

Caradonna, K. L., Engel, J. C., Jacobi, D., Lee, C. H., and Burleigh, B. A. (2013). Host metabolism regulates intracellular growth of Trypanosoma cruzi. Cell Host Microbe. 13, 108-117. doi: 10.1016/j.chom.2012.11.011

Casey, S. C., Amedei, A., Aquilano, K., Azmi, A. S., Benencia, F., Bhakta, D., et al. (2015). Cancer prevention and therapy through the modulation of the tumor microenvironment. Semin. Cancer Biol. 35(Suppl.), S199-S223. doi: 10.1016/j. semcancer.2015.02.007

Castro, J. A., de Mecca, M. M., and Bartel, L. C. (2006). Toxic side effects of drugs used to treat Chagas' disease (American trypanosomiasis). Hum. Exp. Toxicol. 25, 471-479. doi: 10.1191/0960327106het653oa 
Centers for Disease Control and Prevention (2013). Neglected Tropical Diseases. Available at: https://www.cdc.gov/parasites/leishmaniasis/index.html

Centers for Disease Control and Prevention (2016). Parasite-African Trypanosomiasis. Available at: https://www.cdc.gov/parasites/sleepingsickness/

Centers for Disease Control and Prevention (2017). Neglected Tropical Diseases. Available at: https://www.cdc.gov/globalhealth/ntd/

Chakrabarty, Y., and Bhattacharyya, S. N. (2017). Leishmania donovani restricts mitochondrial dynamics to enhance miRNP stability and target RNA repression in host macrophages. Mol. Biol. Cell 28, 2091-2105. doi: 10.1091/mbc.E16-060388

Chappuis, F., Sundar, S., Hailu, A., Ghalib, H., Rijal, S., Peeling, R. W., et al. (2007). Visceral leishmaniasis: what are the needs for diagnosis, treatment and control? Nat. Rev. Microbiol. 5, 873-882. doi: 10.1038/nrmicro1748

Charan Raja, M. R., Velappan, A. B., Chellappan, D., Debnath, J., and Kar Mahapatra, S. (2017). Eugenol derived immunomodulatory molecules against visceral leishmaniasis. Eur. J. Med. Chem. 139, 503-518. doi: 10.1016/j.ejmech. 2017.08.030

Charmoy, M., Hurrell, B. P., Romano, A., Lee, S. H., Ribeiro-Gomes, F., Riteau, N., et al. (2016). The Nlrp3 inflammasome, IL-1beta, and neutrophil recruitment are required for susceptibility to a nonhealing strain of Leishmania major in C57BL/6 mice. Eur. J. Immunol. 46, 897-911. doi: 10.1002/eji.20154 6015

Chekwube, A. I., Onyema, E. I., Ikenna, U. E., and Ezeokonkwo, R. C. (2014). Effect of diminazene aceturate, levamisole and vitamin $\mathrm{C}$ combination therapy in rats experimentally infected with Trypanosoma brucei brucei. Asian Pac. J. Trop. Med. 7, 438-445. doi: 10.1016/S1995-7645(14)60071-7

Cheung, J. L., Wand, N. V., Ooi, C. P., Ridewood, S., Wheeler, R. J., and Rudenko, G. (2016). Blocking synthesis of the variant surface glycoprotein coat in Trypanosoma brucei leads to an increase in macrophage phagocytosis due to reduced clearance of surface coat antibodies. PLoS Pathog. 12:e1006023. doi: 10.1371/journal.ppat.1006023

Cho, Y. C., Lee, S. H., Lee, M., Kim, H. J., Oak, M. H., Lee, I. S., et al. (2012). Enhanced IL-12p40 production in LPS-stimulated macrophages by inhibiting JNK activation by artemisinin. Arch. Pharm. Res. 35, 1961-1968. doi: 10.1007/ s12272-012-1113-8

Combs, T. P., Nagajyothi, Mukherjee, S., de Almeida, C. J., Jelicks, L. A., Schubert, W., et al. (2005). The adipocyte as an important target cell for Trypanosoma cruzi infection. J. Biol. Chem. 280, 24085-24094. doi: 10.1074/ jbc.M412802200

Contreras, I., Estrada, J. A., Guak, H., Martel, C., Borjian, A., Ralph, B., et al. (2014). Impact of Leishmania mexicana infection on dendritic cell signaling and functions. PLoS Negl. Trop. Dis. 8:e3202. doi: 10.1371/journal.pntd.0003202

Courtin, D., Jamonneau, V., Mathieu, J. F., Koffi, M., Milet, J., Yeminanga, C. S., et al. (2006). Comparison of cytokine plasma levels in human African trypanosomiasis. Trop. Med. Int. Health 11, 647-653. doi: 10.1111/j.1365-3156. 2006.01612.x

Croxford, J. L., Wang, K., Miller, S. D., Engman, D. M., and Tyler, K. M. (2005). Effects of cannabinoid treatment on Chagas disease pathogenesis: balancing inhibition of parasite invasion and immunosuppression. Cell Microbiol. 7, 1592-1602. doi: 10.1111/j.1462-5822.2005.00577.x

Cummings, H. E., Barbi, J., Reville, P., Oghumu, S., Zorko, N., Sarkar, A., et al. (2012). Critical role for phosphoinositide 3-kinase gamma in parasite invasion and disease progression of cutaneous leishmaniasis. Proc. Natl. Acad. Sci. U.S.A. 109, 1251-1256. doi: 10.1073/pnas.1110339109

da Costa-Silva, T. A., Grecco, S. S., de Sousa, F. S., Lago, J. H., Martins, E. G., Terrazas, C. A., et al. (2015). Immunomodulatory and antileishmanial activity of phenylpropanoid dimers isolated from Nectandra leucantha. J. Nat. Prod. 78, 653-657. doi: 10.1021/np500809a

da Silva, C. F., Batista Dda, G., De Araujo, J. S., Batista, M. M., Lionel, J., de Souza, E. M., et al. (2013). Activities of psilostachyin A and cynaropicrin against Trypanosoma cruzi in vitro and in vivo. Antimicrob. Agents Chemother. 57, 5307-5314. doi: 10.1128/AAC.00595-13

Das, A., Jawed, J. J., Das, M. C., Sandhu, P., De, U. C., Dinda, B., et al. (2017). Antileishmanial and immunomodulatory activities of lupeol, a triterpene compound isolated from Sterculia villosa. Int. J. Antimicrob. Agents 50, 512-522. doi: 10.1016/j.jijantimicag.2017.04.022

Das, R., Bhattacharya, K., Samanta, S. K., Pal, B. C., and Mandal, C. (2014). Improved chemosensitivity in cervical cancer to cisplatin: synergistic activity of mahanine through STAT3 inhibition. Cancer Lett. 351, 81-90. doi: 10.1016/j. canlet.2014.05.005

Dayakar, A., Chandrasekaran, S., Veronica, J., and Maurya, R. (2016). Leptin induces the phagocytosis and protective immune response in Leishmania donovani infected THP-1 cell line and human PBMCs. Exp. Parasitol. 160, 54-59. doi: 10.1016/j.exppara.2015.12.002

de Barros, N. B., Aragao Macedo, S. R., Ferreira, A. S., Tagliari, M. P., Kayano, A. M., Nicolete, L. D. F., et al. (2018). ASP49-phospholipase A2-loaded liposomes as experimental therapy in cutaneous leishmaniasis model. Int. Immunopharmacol. 55, 128-132. doi: 10.1016/j.intimp.2017.12.012

De Muylder, G., Vanhollebeke, B., Caljon, G., Wolfe, A. R., McKerrow, J., and Dujardin, J. C. (2016). Naloxonazine, an amastigote-specific compound, affects leishmania parasites through modulation of host-encoded functions. PLoS Negl. Trop. Dis. 10:e0005234. doi: 10.1371/journal.pntd.0005234

de Souza, W., de Carvalho, T. M., and Barrias, E. S. (2010). Review on Trypanosoma cruzi: host cell interaction. Int. J. Cell Biol. 2010:295394. doi: 10.1155/2010/ 295394

Diaz-Gonzalez, R., Kuhlmann, F. M., Galan-Rodriguez, C., Madeira, da Silva, L., Saldivia, M., et al. (2011). The susceptibility of trypanosomatid pathogens to PI3/mTOR kinase inhibitors affords a new opportunity for drug repurposing. PLoS Negl. Trop. Dis. 5:e1297. doi: 10.1371/journal.pntd.0001297

Dos Santos, Thomazelli, A. P. F., Tomiotto-Pellissier, F., da Silva, S. S., Panis, C., Orsini, T. M., et al. (2017). Brazilian propolis promotes immunomodulation on human cells from American Tegumentar Leishmaniasis patients and healthy donors infected with L. braziliensis. Cell Immunol. 311, 22-27. doi: 10.1016/j. cellimm.2016.09.014

Drury, R. E., O'Connor, D., and Pollard, A. J. (2017). The clinical application of MicroRNAs in infectious disease. Front. Immunol. 8:1182. doi: 10.3389/fimmu. 2017.01182

Dubovsky, J. A., Beckwith, K. A., Natarajan, G., Woyach, J. A., Jaglowski, S., Zhong, Y., et al. (2013). Ibrutinib is an irreversible molecular inhibitor of ITK driving a Th1-selective pressure in T lymphocytes. Blood 122, 2539-2549. doi: 10.1182/blood-2013-06-507947

Ellis, S., Sexton, D. W., and Steverding, D. (2015). Trypanotoxic activity of thiosemicarbazone iron chelators. Exp. Parasitol. 150, 7-12. doi: 10.1016/j. exppara.2015.01.004

Elshafie, E. I., Sani, R. A., Hassan, L., Sharma, R., Bashir, A., and Abubakar, I. A. (2013). Active infection and morphometric study of Trypanosoma evansi among horses in Peninsula Malaysia. Trop. Biomed. 30, 444-450.

Eugene, D. (1987). Fast non-cholinergic depolarizing postsynaptic potentials in neurons of rat superior cervical ganglia. Neurosci. Lett. 78, 51-56. doi: 10.1016/ 0304-3940(87)90560-X

Feng, G. J., Goodridge, H. S., Harnett, M. M., Wei, X. Q., Nikolaev, A. V., Higson, A. P., et al. (1999). Extracellular signal-related kinase (ERK) and p38 mitogen-activated protein (MAP) kinases differentially regulate the lipopolysaccharide-mediated induction of inducible nitric oxide synthase and IL-12 in macrophages: leishmania phosphoglycans subvert macrophage IL-12 production by targeting ERK MAP kinase. J. Immunol. 163, 6403-6412.

Fernandez-Cortes, F., Serafim, T. D., Wilkes, J. M., Jones, N. G., Ritchie, R., McCulloch, R., et al. (2017). RNAi screening identifies Trypanosoma brucei stress response protein kinases required for survival in the mouse. Sci. Rep. 7:6156. doi: 10.1038/s41598-017-06501-8

Franco, J. R., Simarro, P. P., Diarra, A., and Jannin, J. G. (2014). Epidemiology of human African trypanosomiasis. Clin. Epidemiol. 6, 257-275. doi: 10.2147/ CLEP.S39728

Frank, B., Marcu, A., de Oliveira Almeida Petersen, A. L., Weber, H., Stigloher, C., Mottram, J. C., et al. (2015). Autophagic digestion of Leishmania major by host macrophages is associated with differential expression of BNIP3, CTSE, and the miRNAs miR-101c, miR-129, and miR-210. Parasit. Vectors 8:404. doi: 10.1186/s13071-015-0974-3

Geraci, N. S., Tan, J. C., and McDowell, M. A. (2015). Characterization of microRNA expression profiles in Leishmania-infected human phagocytes. Parasit. Immunol. 37, 43-51. doi: 10.1111/pim.12156

Giordani, F., Morrison, L. J., Rowan, T. G., De Koning, H. P., and Barrett, M. P. (2016). The animal trypanosomiases and their chemotherapy: a review. Parasitology 143, 1862-1889. doi: 10.1017/S00311820160 01268 
Goncalves, M. D., Bortoleti, B. T. S., Tomiotto-Pellissier, F., Miranda-Sapla, M. M., Assolini, J. P., Carloto, A. C. M., et al. (2018). Dehydroabietic acid isolated from Pinus elliottii exerts in vitro antileishmanial action by pro-oxidant effect, inducing ROS production in promastigote and downregulating $\mathrm{Nrf} 2 /$ ferritin expression in amastigote forms of Leishmania amazonensis. Fitoterapia 128, 224-232. doi: 10.1016/j.fitote.2018.05.027

Greuber, E. K., and Pendergast, A. M. (2012). Abl family kinases regulate FcgammaR-mediated phagocytosis in murine macrophages. J. Immunol. 189, 5382-5392. doi: 10.4049/jimmunol.1200974

Guyett, P. J., Behera, R., Ogata, Y., Pollastri, M., and Mensa-Wilmot, K. (2017). Novel effects of lapatinib revealed in the african trypanosome by using hypothesis-generating proteomics and chemical biology strategies. Antimicrob. Agents Chemother. 61:e01865-16. doi: 10.1128/AAC. 01865-16

Harhay, M. O., Olliaro, P. L., Costa, D. L., and Costa, C. H. (2011). Urban parasitology: visceral leishmaniasis in Brazil. Trends Parasitol. 27, 403-409. doi: 10.1016/j.pt.2011.04.001

Harrison, C. (2012). Trial watch: BTK inhibitor shows positive results in B cell malignancies. Nat. Rev. Drug Discov. 11:96. doi: 10.1038/nrd3656

Hertz, C. J., Filutowicz, H., and Mansfield, J. M. (1998). Resistance to the African trypanosomes is IFN-gamma dependent. J. Immunol. 161, 6775-6783.

Hespanhol, R. C., de Nazare, C. S. M., Meuser, M. B., de Nazareth, S. L. M. M., and Corte-Real, S. (2005). The expression of mannose receptors in skin fibroblast and their involvement in Leishmania (L.) amazonensis invasion. J. Histochem. Cytochem. 53, 35-44. doi: 10.1177/002215540505300105

Horn, D. (2014). Antigenic variation in African trypanosomes. Mol. Biochem. Parasitol. 195, 123-129. doi: 10.1016/j.molbiopara.2014.05.001

Hotez, P. J. (2017). Ten failings in global neglected tropical diseases control. PLoS Negl. Trop. Dis. 11:e0005896. doi: 10.1371/journal.pntd.0005896

Hotez, P. J., Molyneux, D. H., Fenwick, A., Kumaresan, J., Sachs, S. E., Sachs, J. D., et al. (2007). Control of neglected tropical diseases. N. Engl. J. Med. 357, 1018-1027. doi: 10.1056/NEJMra064142

Hurrell, B. P., Schuster, S., Grun, E., Coutaz, M., Williams, R. A., Held, W., et al. (2015). Rapid sequestration of Leishmania mexicana by neutrophils contributes to the development of Chronic Lesion. PLoS Pathog. 11:e1004929. doi: 10.1371/ journal.ppat.1004929

Ibrahim, M. A., Bindawa Isah, M., and Abdullahi Salman, A. (2016). Antioxidant therapy against trypanosome infections: a review update. Curr. Top. Med. Chem. 16, 2233-2244. doi: 10.2174/1568026616666160413125622

Ilboudo, H., Bras-Goncalves, R., Camara, M., Flori, L., Camara, O., Sakande, H., et al. (2014). Unravelling human trypanotolerance: IL8 is associated with infection control whereas IL10 and TNFalpha are associated with subsequent disease development. PLoS Pathog. 10:e1004469. doi: 10.1371/journal.ppat. 1004469

Islamuddin, M., Chouhan, G., Want, M. Y., Ozbak, H. A., Hemeg, H. A., and Afrin, F. (2016). Immunotherapeutic potential of eugenol emulsion in experimental visceral leishmaniasis. PLoS Negl. Trop. Dis. 10:e0005011. doi: 10.1371/journal.pntd.0005011

Jacobs, R. T., Nare, B., Wring, S. A., Orr, M. D., Chen, D., Sligar, J. M., et al. (2011). SCYX-7158, an orally-active benzoxaborole for the treatment of stage 2 human African trypanosomiasis. PLoS Negl. Trop. Dis. 5:e1151. doi: 10.1371/journal. pntd.0001151

Jamal, R., Shimogawara, R., Yamamoto, K., and Ohta, N. (2016). Anti-trypanosome effects of nutritional supplements and vitamin D3: in vitro and in vivo efficacy against Trypanosoma brucei brucei. Trop. Med. Health 44:26. doi: 10.1186/ s41182-016-0024-7

Jhingran, A., Chawla, B., Saxena, S., Barrett, M. P., and Madhubala, R. (2009). Paromomycin: uptake and resistance in Leishmania donovani. Mol. Biochem. Parasitol. 164, 111-117. doi: 10.1016/j.molbiopara.2008.12.007

Jin, J. O., Zhang, W., Du, J. Y., Wong, K. W., Oda, T., and Yu, Q. (2014). Fucoidan can function as an adjuvant in vivo to enhance dendritic cell maturation and function and promote antigen-specific $\mathrm{T}$ cell immune responses. PLoS One 9:e99396. doi: 10.1371/journal.pone.0099396

Kalil-Filho, R. (2015). Globalization of Chagas disease burden and new treatment perspectives. J. Am. Coll. Cardiol. 66, 1190-1192. doi: 10.1016/j.jacc.2015.07.024

Kar, S., Sharma, G., and Das, P. K. (2011). Fucoidan cures infection with both antimony-susceptible and -resistant strains of Leishmania donovani through
Th1 response and macrophage-derived oxidants. J. Antimicrob. Chemother. 66, 618-625. doi: 10.1093/jac/dkq502

Kato, C. D., Alibu, V. P., Nanteza, A., Mugasa, C. M., and Matovu, E. (2015). Interleukin (IL)-6 and IL-10 are up regulated in late stage Trypanosoma brucei rhodesiense sleeping sickness. PLoS Negl. Trop. Dis. 9:e0003835. doi: 10.1371/ journal.pntd.0003835

Kato, C. D., Matovu, E., Mugasa, C. M., Nanteza, A., and Alibu, V. P. (2016). The role of cytokines in the pathogenesis and staging of Trypanosoma brucei rhodesiense sleeping sickness. Allergy Asthma Clin. Immunol. 12:4. doi: 10. 1186/s13223-016-0113-5

Kaur, G., Jabbar, Z., Athar, M., and Alam, M. S. (2006). Punica granatum (pomegranate) flower extract possesses potent antioxidant activity and abrogates Fe-NTA induced hepatotoxicity in mice. Food Chem. Toxicol. 44, 984-993. doi: 10.1016/j.fct.2005.12.001

Kawano, D. F., Silva, V. B., Jorge, D. M., Silva, C. H., and Carvalho, I. (2011). Search for a platelet-activating factor receptor in the Trypanosoma cruzi proteome: a potential target for Chagas disease chemotherapy. Mem. Inst. Oswaldo Cruz 106, 957-967. doi: 10.1590/S0074-02762011000800010

Kelada, S., Sethupathy, P., Okoye, I. S., Kistasis, E., Czieso, S., White, S. D., et al. (2013). miR-182 and miR-10a are key regulators of Treg specialisation and stability during Schistosome and Leishmania-associated inflammation. PLoS Pathog. 9:e1003451. doi: 10.1371/journal.ppat.1003451

Kennedy, P. G. (2013). Clinical features, diagnosis, and treatment of human African trypanosomiasis (sleeping sickness). Lancet Neurol. 12, 186-194. doi: 10.1016/S1474-4422(12)70296-X

Khadem, F., Jia, P., Mou, Z., Feiz Barazandeh, A., Liu, D., Keynan, Y., et al. (2017). Pharmacological inhibition of p110delta subunit of PI3K confers protection against experimental leishmaniasis. J. Antimicrob. Chemother. 72, 467-477. doi: 10.1093/jac/dkw448

Klotz, S. A., Dorn, P. L., Mosbacher, M., and Schmidt, J. O. (2014). Kissing bugs in the United States: risk for vector-borne disease in humans. Environ. Health Insights 8(Suppl. 2), 49-59. doi: 10.4137/EHI.S16003

Krishnan, M. N., and Garcia-Blanco, M. A. (2014). Targeting host factors to treat West Nile and dengue viral infections. Viruses 6, 683-708. doi: 10.3390/ v6020683

Kulkarni, M. M., Varikuti, S., Terrazas, C., Kimble, J. L., Satoskar, A. R., and McGwire, B. S. (2015). Signal transducer and activator of transcription 1 (STAT1) plays a critical role in control of Trypanosoma cruzi infection. Immunology 145, 225-231. doi: 10.1111/imm.12438

Kumar, G. A., Roy, S., Jafurulla, M., Mandal, C., and Chattopadhyay, A. (2016). Statin-induced chronic cholesterol depletion inhibits Leishmania donovani infection: relevance of optimum host membrane cholesterol. Biochim. Biophys. Acta 1858, 2088-2096. doi: 10.1016/j.bbamem.2016.06.010

Kyriazis, I. D., Koutsoni, O. S., Aligiannis, N., Karampetsou, K., Skaltsounis, A. L., and Dotsika, E. (2016). The leishmanicidal activity of oleuropein is selectively regulated through inflammation- and oxidative stress-related genes. Parasit. Vectors 9:441. doi: 10.1186/s13071-016-1701-4

Lamotte, S., Spath, G. F., Rachidi, N., and Prina, E. (2017). The enemy within: targeting host-parasite interaction for antileishmanial drug discovery. PLoS Negl. Trop. Dis. 11:e0005480. doi: 10.1371/journal.pntd.0005480

Lee, H., Pal, S. K., Reckamp, K., Figlin, R. A., and Yu, H. (2011). STAT3: a target to enhance antitumor immune response. Curr. Top. Microbiol. Immunol. 344, 41-59. doi: 10.1007/82_2010_51

Leppert, B. J., Mansfield, J. M., and Paulnock, D. M. (2007). The soluble variant surface glycoprotein of African trypanosomes is recognized by a macrophage scavenger receptor and induces I kappa B alpha degradation independently of TRAF6-mediated TLR signaling. J. Immunol. 179, 548-556. doi: 10.4049/ jimmunol.179.1.548

Li, C. G., Yan, L., Jing, Y. Y., Xu, L. H., Liang, Y. D., Wei, H. X., et al. (2017). Berberine augments ATP-induced inflammasome activation in macrophages by enhancing AMPK signaling. Oncotarget 8, 95-109. doi: 10.18632/oncotarget. 13921

Liepinsh, E., Vilskersts, R., Loca, D., Kirjanova, O., Pugovichs, O., Kalvinsh, I., et al. (2006). Mildronate, an inhibitor of carnitine biosynthesis, induces an increase in gamma-butyrobetaine contents and cardioprotection in isolated rat heart infarction. J. Cardiovasc. Pharmacol. 48, 314-319. doi: 10.1097/01.fjc. 0000250077.07702 .23 
Locksley, R. M., Pingel, S., Lacy, D., Wakil, A. E., Bix, M., and Fowell, D. J. (1999). Susceptibility to infectious diseases: leishmania as a paradigm. J. Infect. Dis. 179(Suppl. 2), S305-S308. doi: 10.1086/513843

Lovo-Martins, M. I., Malvezi, A. D., da Silva, R. V., Zanluqui, N. G., Tatakihara, V. L. H., Camara, N. O. S., et al. (2017). Fish oil supplementation benefits the murine host during the acute phase of a parasitic infection from Trypanosoma cruzi. Nutr. Res. 41, 73-85. doi: 10.1016/j.nutres.2017.04.007

Lu, F., and Huang, S. (2017). The roles of mast cells in parasitic protozoan infections. Front. Immunol. 8:363. doi: 10.3389/fimmu.2017.00363

Maia, C., and Cardoso, L. (2015). Spread of leishmania infantum in Europe with dog travelling. Vet. Parasitol. 213, 2-11. doi: 10.1016/j.vetpar.2015. 05.003

Mathur, R. K., Awasthi, A., Wadhone, P., Ramanamurthy, B., and Saha, B. (2004). Reciprocal CD40 signals through p38MAPK and ERK-1/2 induce counteracting immune responses. Nat. Med. 10, 540-544. doi: 10.1038/nm 1045

Maurya, R., Bhattacharya, P., Ismail, N., Dagur, P. K., Joshi, A. B., Razdan, K., et al. (2016). Differential role of leptin as an immunomodulator in controlling visceral leishmaniasis in normal and leptin-deficient mice. Am. J. Trop. Med. Hyg. 95, 109-119. doi: 10.4269/ajtmh.15-0804

McCall, L. I., Zhang, W. W., and Matlashewski, G. (2013). Determinants for the development of visceral leishmaniasis disease. PLoS Pathog. 9:e1003053. doi: 10.1371/journal.ppat.1003053

McFarlane, E., Carter, K. C., McKenzie, A. N., Kaye, P. M., Brombacher, F., and Alexander, J. (2011). Endogenous IL-13 plays a crucial role in liver granuloma maturation during Leishmania donovani infection, independent of IL-4Ralpharesponsive macrophages and neutrophils. J. Infect. Dis. 204, 36-43. doi: 10.1093/ infdis/jir080

McGwire, B. S., and Satoskar, A. R. (2014). Leishmaniasis: clinical syndromes and treatment. QJM 107, 7-14. doi: 10.1093/qjmed/hct116

Mello, J., Gomes, R. A., Vital-Fujii, D. G., Ferreira, G. M., and Trossini, G. H. G. (2017). Fragment-based drug discovery as alternative strategy to the drug development for neglected diseases. Chem. Biol. Drug Des. 90, 1067-1078. doi: $10.1111 /$ cbdd. 13030

Mesa, L. E., Vasquez, D., Lutgen, P., Velez, I. D., Restrepo, A. M., Ortiz, I., et al. (2017). In vitro and in vivo antileishmanial activity of Artemisia annua L. leaf powder and its potential usefulness in the treatment of uncomplicated cutaneous leishmaniasis in humans. Rev. Soc. Bras. Med. Trop. 50, 52-60. doi: 10.1590/0037-8682-0457-2016

Mesu, V., Kalonji, W. M., Bardonneau, C., Mordt, O. V., Blesson, S., Simon, F., et al. (2018). Oral fexinidazole for late-stage African Trypanosoma brucei gambiense trypanosomiasis: a pivotal multicentre, randomised, non-inferiority trial. Lancet 391, 144-154. doi: 10.1016/S0140-6736(17)32758-7

Meyers, A. C., Meinders, M., and Hamer, S. A. (2017). Widespread Trypanosoma cruzi infection in government working dogs along the texas-mexico border: discordant serology, parasite genotyping and associated vectors. PLoS Negl. Trop. Dis. 11:e0005819. doi: 10.1371/journal.pntd.0005819

Millan, J., Ferroglio, E., and Solano-Gallego, L. (2014). Role of wildlife in the epidemiology of leishmania infantum infection in Europe. Parasitol. Res. 113, 2005-2014. doi: 10.1007/s00436-014-3929-2

Miranda, M. M., Panis, C., Cataneo, A. H., da Silva, S. S., Kawakami, N. Y., Lopes, L. G., et al. (2015). Nitric oxide and Brazilian propolis combined accelerates tissue repair by modulating cell migration, cytokine production and collagen deposition in experimental leishmaniasis. PLoS One 10:e0125101. doi: 10.1371/ journal.pone.0125101

Mittra, B., Saha, A., Chowdhury, A. R., Pal, C., Mandal, S., Mukhopadhyay, S., et al. (2000). Luteolin, an abundant dietary component is a potent antileishmanial agent that acts by inducing topoisomerase II-mediated kinetoplast DNA cleavage leading to apoptosis. Mol. Med. 6, 527-541. doi: 10.1007/ BF03401792

Moreira, V., Lomonte, B., Vinolo, M. A., Curi, R., Gutierrez, J. M., and Teixeira, C. (2014). An Asp49 phospholipase A2 from snake venom induces cyclooxygenase-2 expression and prostaglandin E2 production via activation of NF-kappaB, p38MAPK, and PKC in macrophages. Mediators Inflamm. 2014:105879. doi: 10.1155/2014/105879

Mougneau, E., Bihl, F., and Glaichenhaus, N. (2011). Cell biology and immunology of Leishmania. Immunol. Rev. 240, 286-296. doi: 10.1111/j.1600-065X.2010. 00983.x
Murakami, M., and Kudo, I. (2002). Phospholipase A2. J. Biochem. 131, 285-292. doi: 10.1093/oxfordjournals.jbchem.a003101

Naman, C. B., Gomes, C. M., and Gupta, G. (2018). Phytodrugs and immunomodulators for the therapy of Leishmaniasis. Nat. Prod. Drug Discov. 231-275. doi: 10.1016/B978-0-08-102081-4.00009-5

Noori, S., and Hassan, Z. M. (2011). Dihydroartemisinin shift the immune response towards Th1, inhibit the tumor growth in vitro and in vivo. Cell Immunol. 271, 67-72. doi: 10.1016/j.cellimm.2011.06.008

Nzoumbou-Boko, R., De Muylder, G., Semballa, S., Lecordier, L., Dauchy, F. A., Gobert, A. P., et al. (2017). Trypanosoma musculi infection in mice critically relies on mannose receptor-mediated arginase induction by a TbKHC1 kinesin H chain homolog. J. Immunol. 199, 1762-1771. doi: 10.4049/jimmunol.1700179

Odiit, M., Kansiime, F., and Enyaru, J. C. (1997). Duration of symptoms and case fatality of sleeping sickness caused by Trypanosoma brucei rhodesiense in Tororo. Uganda. East Afr. Med. J. 74, 792-795.

Oghumu, S., Varikuti, S., Saljoughian, N., Terrazas, C., Huntsman, A. C., Parinandi, N. L., et al. (2017). Pentalinonsterol, a constituent of pentalinon andrieuxii, possesses potent immunomodulatory activity and primes $\mathrm{t}$ cell immune responses. J. Nat. Prod. 80, 2515-2523. doi: 10.1021/acs.jnatprod.7b00445

Olliaro, P., and Sundar, S. (2009). Anthropometrically derived dosing and drug costing calculations for treating visceral leishmaniasis in Bihar, India. Trop. Med. Int. Health 14, 88-92. doi: 10.1111/j.1365-3156.2008.02195.x

Onyilagha, C., Kuriakose, S., Ikeogu, N., Jia, P., and Uzonna, J. (2018). Myeloidderived suppressor cells contribute to susceptibility to Trypanosoma congolense infection by suppressing CD4 $(+) \mathrm{T}$ cell proliferation and IFN-gamma production. J. Immunol. 201, 507-515. doi: 10.4049/jimmunol.1800180

Otta, D. A., de Araujo, F. F., de Rezende, V. B., Souza-Fagundes, E. M., Eloi-Santos, S. M., Costa-Silva, M. F., et al. (2018). Identification of anti-Trypanosoma cruzi lead compounds with putative immunomodulatory activity. Antimicrob. Agents Chemother. 62, e1834-e1817. doi: 10.1128/AAC.01834-17

Pace, D. (2014). Leishmaniasis. J. Infect. 69(Suppl. 1), S10-S18. doi: 10.1016/j.jinf. 2014.07.016

Pan, Z., Scheerens, H., Li, S. J., Schultz, B. E., Sprengeler, P. A., Burrill, L. C., et al. (2007). Discovery of selective irreversible inhibitors for Bruton's tyrosine kinase. Chem. Med. Chem. 2, 58-61. doi: 10.1002/cmdc.200600221

Papadopoulou, M. V., Bloomer, W. D., Rosenzweig, H. S., and Kaiser, M. (2017). The antitrypanosomal and antitubercular activity of some nitro(triazole/imidazole)-based aromatic amines. Eur. J. Med. Chem. 138, 1106-1113. doi: 10.1016/j.ejmech.2017.07.060

Parihar, S. P., Hartley, M. A., Hurdayal, R., Guler, R., and Brombacher, F. (2016). Topical simvastatin as host-directed therapy against severity of cutaneous leishmaniasis in mice. Sci. Rep. 6:33458. doi: 10.1038/srep33458

Parreira, D. R., Jansen, A. M., Abreu, U. G., Macedo, G. C., Silva, A. R., Mazur, C., et al. (2016). Health and epidemiological approaches of Trypanosoma evansi and equine infectious anemia virus in naturally infected horses at southern Pantanal. Acta Trop. 163, 98-102. doi: 10.1016/j.actatropica.2016. 08.005

Paumen, M. B., Ishida, Y., Muramatsu, M., Yamamoto, M., and Honjo, T. (1997). Inhibition of carnitine palmitoyltransferase I augments sphingolipid synthesis and palmitate-induced apoptosis. J. Biol. Chem. 272, 3324-3329. doi: 10.1074/ jbc.272.6.3324

Peters, N. C., Egen, J. G., Secundino, N., Debrabant, A., Kimblin, N., Kamhawi, S., et al. (2008). In vivo imaging reveals an essential role for neutrophils in leishmaniasis transmitted by sand flies. Science 321, 970-974. doi: 10.1126/ science. 1159194

Petersen, C. A., Krumholz, K. A., Carmen, J., Sinai, A. P., and Burleigh, B. A. (2006). Trypanosoma cruzi infection and nuclear factor kappa B activation prevent apoptosis in cardiac cells. Infect. Immun. 74, 1580-1587. doi: 10.1128/IAI.74. 3.1580-1587.2006

Ponte-Sucre, A., Gamarro, F., Dujardin, J. C., Barrett, M. P., Lopez-Velez, R., Garcia-Hernandez, R., et al. (2017). Drug resistance and treatment failure in leishmaniasis: a 21st century challenge. PLoS Negl. Trop. Dis. 11:e0006052. doi: 10.1371/journal.pntd.0006052

Priotto, G., Kasparian, S., Mutombo, W., Ngouama, D., Ghorashian, S., Arnold, U., et al. (2009). Nifurtimox-eflornithine combination therapy for secondstage African Trypanosoma brucei gambiense trypanosomiasis: a multicentre, randomised, phase III, non-inferiority trial. Lancet 374, 56-64. doi: 10.1016/ S0140-6736(09)61117-X 
Prudencio, M., and Mota, M. M. (2013). Targeting host factors to circumvent anti-malarial drug resistance. Curr. Pharm. Des. 19, 290-299. doi: 10.2174/ 138161213804070276

Rassi, A. Jr., Rassi, A., and Marin-Neto, J. A. (2010). Chagas disease. Lancet 375, 1388-1402. doi: 10.1016/S0140-6736(10)60061-X

Ravinetto, R., Alirol, E., Mahendradhata, Y., Rijal, S., Lutumba, P., Sacko, M., et al. (2016). Clinical research in neglected tropical diseases: the challenge of implementing good clinical (Laboratory) practices. PLoS Negl. Trop. Dis. 10:e0004654. doi: 10.1371/journal.pntd.0004654

Ready, P. D. (2014). Epidemiology of visceral leishmaniasis. Clin. Epidemiol. 6, 147-154. doi: 10.2147/CLEP.S44267

Ronco, M. T., Frances, D. E., Ingaramo, P. I., Quiroga, A. D., Alvarez, M. L., Pisani, G. B., et al. (2010). Tumor necrosis factor alpha induced by Trypanosoma cruzi infection mediates inflammation and cell death in the liver of infected mice. Cytokine 49, 64-72. doi: 10.1016/j.cyto.2009.09.012

Roy, S., Dutta, D., Satyavarapu, E. M., Yadav, P. K., Mandal, C., Kar, S., et al. (2017). Mahanine exerts in vitro and in vivo antileishmanial activity by modulation of redox homeostasis. Sci. Rep. 7:4141. doi: 10.1038/s41598-01703943-y

Sabbah, H. H., and Stanley, W. C. (2002). Partial fatty acid oxidation inhibitors: a potentially new class of drugs for heart failure. Eur. J. Heart Fail. 4, 3-6. doi: 10.1016/S1388-9842(01)00183-0

Saha, P., Bhattacharjee, S., Sarkar, A., Manna, A., Majumder, S., and Chatterjee, M. (2011). Berberine chloride mediates its anti-leishmanial activity via differential regulation of the mitogen activated protein kinase pathway in macrophages. PLoS One 6:e18467. doi: 10.1371/journal.pone.0018467

Sanchez-Guillen Mdel, C., Lopez-Colombo, A., Ordonez-Toquero, G., GomezAlbino, I., Ramos-Jimenez, J., Torres-Rasgado, E., et al. (2006). Clinical forms of Trypanosoma cruzi infected individuals in the chronic phase of Chagas disease in Puebla, Mexico. Mem. Inst. Oswaldo Cruz 101, 733-740. doi: 10.1590/S007402762006000700005

Satoskar, A., Bluethmann, H., and Alexander, J. (1995). Disruption of the murine interleukin-4 gene inhibits disease progression during Leishmania mexicana infection but does not increase control of Leishmania donovani infection. Infect. Immun. 63, 4894-4899.

Scharfstein, J., Schmitz, V., Morandi, V., Capella, M. M., Lima, A. P., Morrot, A., et al. (2000). Host cell invasion by Trypanosoma cruzi is potentiated by activation of bradykinin B(2) receptors. J. Exp. Med. 192, 1289-1300. doi: 10. 1084/jem.192.9.1289

Seixas, J. D., Luengo-Arratta, S. A., Diaz, R., Saldivia, M., Rojas-Barros, D. I., Manzano, P., et al. (2014). Establishment of a structure-activity relationship of $1 \mathrm{H}$-imidazo[4,5-c] quinoline-based kinase inhibitor NVP-BEZ235 as a lead for African sleeping sickness. J. Med. Chem. 57, 4834-4848. doi: 10.1021/jm50 $0361 \mathrm{r}$

Selby, R., Bardosh, K., Picozzi, K., Waiswa, C., and Welburn, S. C. (2013). Cattle movements and trypanosomes: restocking efforts and the spread of Trypanosoma brucei rhodesiense sleeping sickness in post-conflict Uganda. Parasit. Vectors 6:281. doi: 10.1186/1756-3305-6-281

Sharma, G., Kar, S., Basu Ball, W., Ghosh, K., and Das, P. K. (2014). The curative effect of fucoidan on visceral leishmaniasis is mediated by activation of MAP kinases through specific protein kinase C isoforms. Cell Mol. Immunol. 11, 263-274. doi: 10.1038/cmi.2013.68

Shi, M., Pan, W., and Tabel, H. (2003). Experimental African trypanosomiasis: IFNgamma mediates early mortality. Eur. J. Immunol. 33, 108-118. doi: 10.1002/ immu.200390013

Silva, J. F., Capettini, L. S., da Silva, J. F., Sales-Junior, P., Cruz, J. S., Cortes, S. F., et al. (2016). Mechanisms of vascular dysfunction in acute phase of Trypanosoma cruzi infection in mice. Parasit. Vectors 82, 73-81. doi: 10.1016/j. vph.2016.03.002

Silva, J. S., Twardzik, D. R., and Reed, S. G. (1991). Regulation of Trypanosoma cruzi infections in vitro and in vivo by transforming growth factor beta (TGFbeta). J. Exp. Med. 174, 539-545. doi: 10.1084/jem.174.3.539

Singh, A. K., Pandey, R. K., Shaha, C., and Madhubala, R. (2016). MicroRNA expression profiling of Leishmania donovani-infected host cells uncovers the regulatory role of MIR30A-3p in host autophagy. Autophagy 12, 1817-1831. doi: 10.1080/15548627.2016.1203500

Sirtori, C. R. (2014). The pharmacology of statins. Pharmacol. Res. 88, 3-11. doi: 10.1016/j.phrs.2014.03.002
Smith, P., Ho, C. K., Takagi, Y., Djaballah, H., and Shuman, S. (2016). Nanomolar inhibitors of Trypanosoma brucei RNA Triphosphatase. mBio 7:e00058-16. doi: 10.1128/mBio.00058-16

Stager, S., Alexander, J., Carter, K. C., Brombacher, F., and Kaye, P. M. (2003). Both interleukin-4 (IL-4) and IL-4 receptor alpha signaling contribute to the development of hepatic granulomas with optimal antileishmanial activity. Infect. Immun. 71, 4804-4807. doi: 10.1128/IAI.71.8.4804-4807.2003

Stahl, P., Ruppert, V., Schwarz, R. T., and Meyer, T. (2014). Trypanosoma cruzi evades the protective role of interferon-gamma-signaling in parasite-infected cells. PLoS One 9:e110512. doi: 10.1371/journal.pone.0110512

Steketee, P. C., Vincent, I. M., Achcar, F., Giordani, F., Kim, D. H., Creek, D. J., et al. (2018). Benzoxaborole treatment perturbs S-adenosyl-L-methionine metabolism in Trypanosoma brucei. PLoS Negl. Trop. Dis. 12:e0006450. doi: 10.1371/journal.pntd.0006450

Stijlemans, B., Caljon, G., Van Den Abbeele, J., Van Ginderachter, J. A., Magez, S., and De Trez, C. (2016). Immune evasion strategies of Trypanosoma brucei within the mammalian host: progression to pathogenicity. Front. Immunol. 7:233. doi: 10.3389/fimmu.2016.00233

Sulsen, V. P., Cazorla, S. I., Frank, F. M., Laurella, L. C., Muschietti, L. V., Catalan, C. A., et al. (2013). Natural terpenoids from Ambrosia species are active in vitro and in vivo against human pathogenic trypanosomatids. PLoS Negl. Trop. Dis. 7:e2494. doi: 10.1371/journal.pntd.0002494

Tarleton, R. L. (2015). CD8 + T cells in Trypanosoma cruzi infection. Semin. Immunopathol. 37, 233-238. doi: 10.1007/s00281-015-0481-9

Tarleton, R. L., Grusby, M. J., and Zhang, L. (2000). Increased susceptibility of Stat4-deficient and enhanced resistance in Stat6-deficient mice to infection with Trypanosoma cruzi. J. Immunol. 165, 1520-1525. doi: 10.4049/jimmunol.165.3. 1520

The Center for Food Security and Public Health (2017). Factsheets. Available at: http://www.cfsph.iastate.edu/Factsheets/pdfs/leishmaniasis.pdf

Tiuman, T. S., Santos, A. O., Ueda-Nakamura, T., Filho, B. P., and Nakamura, C. V. (2011). Recent advances in leishmaniasis treatment. Int. J. Infect. Dis. 15, e525-e532. doi: 10.1016/j.ijid.2011.03.021

Todorov, A. G., Andrade, D., Pesquero, J. B., Araujo Rde, C., Bader, M., Stewart, J., et al. (2003). Trypanosoma cruzi induces edematogenic responses in mice and invades cardiomyocytes and endothelial cells in vitro by activating distinct kinin receptor (B1/B2) subtypes. FASEB J. 17, 73-75. doi: 10.1096/fj.02-0477fje

Torrado, J. J., Espada, R., Ballesteros, M. P., and Torrado-Santiago, S. (2008). Amphotericin B formulations and drug targeting. J. Pharm. Sci. 97, 2405-2425. doi: $10.1002 /$ jps.21179

Tyler, K. M., and Engman, D. M. (2001). The life cycle of Trypanosoma cruzi revisited. Int. J. Parasitol. 31, 472-481. doi: 10.1016/S0020-7519(01)00153-9

Villalta, F., Scharfstein, J., Ashton, A. W., Tyler, K. M., Guan, F., Mukherjee, S., et al. (2009). Perspectives on the Trypanosoma cruzi-host cell receptor interactions. Parasitol. Res. 104, 1251-1260. doi: 10.1007/s00436-009-1383-3

Vishwakarma, P., Parmar, N., Chandrakar, P., Sharma, T., Kathuria, M., Agnihotri, P. K., et al. (2018). Ammonium trichloro [1,2-ethanediolato-O,O']-tellurate cures experimental visceral leishmaniasis by redox modulation of Leishmania donovani trypanothione reductase and inhibiting host integrin linked PI3K/Akt pathway. Cell Mol. Life Sci. 75, 563-588. doi: 10.1007/s00018-0172653-3

Voronov, E., Dotan, S., Gayvoronsky, L., White, R. M., Cohen, I., Krelin, Y., et al. (2010). IL-1-induced inflammation promotes development of leishmaniasis in susceptible BALB/c mice. Int. Immunol. 22, 245-257. doi: 10.1093/intimm/ dxq006

Waghabi, M. C., de Souza, E. M., de Oliveira, G. M., Keramidas, M., Feige, J. J. Araujo-Jorge, T. C., et al. (2009). Pharmacological inhibition of transforming growth factor beta signaling decreases infection and prevents heart damage in acute Chagas' disease. Antimicrob. Agents Chemother. 53, 4694-4701. doi: 10.1128/AAC.00580-09

Waghabi, M. C., Keramidas, M., Bailly, S., Degrave, W., Mendonca-Lima, L., Soeiro Mde, N., et al. (2005). Uptake of host cell transforming growth factor-beta by Trypanosoma cruzi amastigotes in cardiomyocytes: potential role in parasite cycle completion. Am. J. Pathol. 167, 993-1003. doi: 10.1016/S0002-9440(10) 61189-3

Waghabi, M. C., Keramidas, M., Calvet, C. M., Meuser, M., de Nazare, C. S. M., Mendonca-Lima, L., et al. (2007). SB-431542, a transforming growth factor beta inhibitor, impairs Trypanosoma cruzi infection in cardiomyocytes and 
parasite cycle completion. Antimicrob. Agents Chemother. 51, 2905-2910. doi: 10.1128/AAC.00022-07

Wall, R. J., Moniz, S., Thomas, M. G., Norval, S., Ko, E. J., Marco, M., et al. (2018). Antitrypanosomal 8-hydroxy-naphthyridines are chelators of divalent transition metals. Antimicrob. Agents Chemother. 62:e00235-18. doi: 10.1128/ AAC.00235-18

Wallukat, G., Munoz Saravia, S. G., Haberland, A., Bartel, S., Araujo, R., Valda, G., et al. (2010). Distinct patterns of autoantibodies against G-protein-coupled receptors in Chagas' cardiomyopathy and megacolon. Their potential impact for early risk assessment in asymptomatic Chagas' patients. J. Am. Coll. Cardiol. 55, 463-468. doi: 10.1016/j.jacc.2009.06.064

Want, M. Y., Islammudin, M., Chouhan, G., Ozbak, H. A., Hemeg, H. A., Chattopadhyay, A. P., et al. (2017). Nanoliposomal artemisinin for the treatment of murine visceral leishmaniasis. Int. J. Nanomed. 12, 2189-2204. doi: 10.2147/IJN.S106548

Want, M. Y., Islamuddin, M., Chouhan, G., Ozbak, H. A., Hemeg, H. A., Dasgupta, A. K., et al. (2015). Therapeutic efficacy of artemisinin-loaded nanoparticles in experimental visceral leishmaniasis. Colloids Surf. B Biointerfaces 130, 215-221. doi: 10.1016/j.colsurfb.2015.04.013

Weina, P. J., Neafie, R. C., Wortmann, G., Polhemus, M., and Aronson, N. E. (2004). Old world leishmaniasis: an emerging infection among deployed US military and civilian workers. Clin. Infect. Dis. 39, 1674-1680. doi: 10.1086/ 425747

Wetzel, D. M., McMahon-Pratt, D., and Koleske, A. J. (2012). The Abl and Arg kinases mediate distinct modes of phagocytosis and are required for maximal Leishmania infection. Mol. Cell. Biol. 32, 3176-3186. doi: 10.1128/MCB. 0008-12

Woelbing, F., Kostka, S. L., Moelle, K., Belkaid, Y., Sunderkoetter, C., Verbeek, S., et al. (2006). Uptake of Leishmania major by dendritic cells is mediated by Fcgamma receptors and facilitates acquisition of protective immunity. J. Exp. Med. 203, 177-188. doi: 10.1084/jem.20052288

Wolkmer, P., Silva, C. B., Paim, F. C., Duarte, M. M., Castro, V., Palma, H. E., et al. (2013). Pre-treatment with curcumin modulates acetylcholinesterase activity and proinflammatory cytokines in rats infected with Trypanosoma evansi. Parasitol. Int. 62, 144-149. doi: 10.1016/j.parint.2012. 11.004

Woodring, J. L., Patel, G., Erath, J., Behera, R., Lee, P. J., Leed, S. E., et al. (2015). Evaluation of aromatic 6-substituted thienopyrimidines as scaffolds against parasites that cause trypanosomiasis, leishmaniasis, and malaria. Medchemcomm 6, 339-346. doi: 10.1039/C4MD00441H
World Health Organization (2013). Control and surveillance of human African trypanosomiasis. World Health Organ. Tech. Rep. Ser. 1-237. Available at: http: //www.who.int/iris/handle/10665/95732

World Health Organization (2016). Global Health Estimates 2015: Disease burden by Cause, Age, Sex, by Country and by Region, 2000-2015. Available at: http: //www.who.int/healthinfo/global_burden_disease/estimates/en/index2.html

World Health Organization (2017). Elimination Sleeping Sickness as a Public Health Problem is on Track. Available at: http://www.who.int/trypanosomiasis_african/ en/

World Health Organization (2018). Neglected Tropical Diseases. Available at: http: //www.who.int/neglected_diseases/en/

Wyllie, S., Foth, B. J., Kelner, A., Sokolova, A. Y., Berriman, M., and Fairlamb, A. H. (2016). Nitroheterocyclic drug resistance mechanisms in Trypanosoma brucei. J. Antimicrob. Chemother. 71, 625-634. doi: 10.1093/jac/dkv376

Yang, M., Ma, C., Sun, J., Shao, Q., Gao, W., Zhang, Y., et al. (2008). Fucoidan stimulation induces a functional maturation of human monocyte-derived dendritic cells. Int. Immunopharmacol. 8, 1754-1760. doi: 10.1016/j.intimp. 2008.08.007

Yasinzai, M., Khan, M., Nadhman, A., and Shahnaz, G. (2013). Drug resistance in leishmaniasis: current drug-delivery systems and future perspectives. Future Med. Chem. 5, 1877-1888. doi: 10.4155/fmc. 13.143

Zhang, N., and Kima, P. E. (2016). Leishmania infection engages non-receptor protein kinases differentially to persist in infected hosts. Front. Immunol. 7:146. doi: 10.3389/fimmu.2016.00146

Zingales, B., Araujo, R. G., Moreno, M., Franco, J., Aguiar, P. H., Nunes, S. L., et al. (2015). A novel ABCG-like transporter of Trypanosoma cruzi is involved in natural resistance to benznidazole. Mem. Inst. Oswaldo Cruz 110, 433-444. doi: 10.1590/0074-02760140407

Conflict of Interest Statement: The authors declare that the research was conducted in the absence of any commercial or financial relationships that could be construed as a potential conflict of interest.

Copyright (c) 2018 Varikuti, Jha, Volpedo, Ryan, Halsey, Hamza, McGwire and Satoskar. This is an open-access article distributed under the terms of the Creative Commons Attribution License (CC BY). The use, distribution or reproduction in other forums is permitted, provided the original author(s) and the copyright owner(s) are credited and that the original publication in this journal is cited, in accordance with accepted academic practice. No use, distribution or reproduction is permitted which does not comply with these terms. 